\title{
LA LEY GENERAL DE EDUCACIÓN DE 1970, ¿UNA LEY PARA LA MODERNIZACIÓN DE ESPAÑA?
}

\author{
The General Education Act of 1970, a law for \\ the modernization of Spain
}

\section{Juan Manuel Fernández-Soria ${ }^{\alpha}$ y Diego Sevilla Merino}

Fecha de recepción: 17/02/2021 • Fecha de aceptación: 02/03/2021

Resumen. El artículo pretende desarrollar aspectos que ayuden a una mejor comprensión de la Ley General de Educación de 1970, y para ello examina los factores que permiten hablar de una Ley para la modernización de España. En este sentido se ha considerado que el rasgo más definitorio de la Ley es su ambición modernizadora del sistema educativo; de ahí que se concrete el concepto «modernización» y se estudien los precedentes y los ejes modernizadores de la Ley. También se ha prestado atención al contexto socioeconómico y político que ayuda a entender mejor su aparición. Dada su importancia, el artículo se detiene en analizar los obstáculos y resistencias que dificultaron su génesis y su aplicación, así como las controversias que han surgido a partir de la reforma que promovió. Finalmente, a modo de discusión, se hace una valoración de la misma teniendo en cuenta los aspectos que conforman el concepto «modernización».

Palabras clave: Legislación escolar; Ley General de Educación de 1970; Modernización del sistema educativo; Reforma educativa; Franquismo y educación.

Abstract. The article aims to examine aspects that help to better understand the General Education Act of 1970 by analyzing the factors that made it a Law

\footnotetext{
a Departamento de Educación Comparada e Historia de la Educación (Facultad de Filosofía y Ciencias de la Educación). Universidad de Valencia. Avenida de Blasco Ibáñez, n. ${ }^{\circ}$ 30. 46010 Valencia. España. Juan.M.Fernandez@uv.es (D) https://orcid.org/0000-0002-1274-0482

B Departamento de Pedagogía (Facultad de Ciencias de la Educación). Universidad de Granada. Campus Universitario de Cartuja. 18071 Granada. España. sevilla@ugr.es (D) https://orcid.org/00000003-3358-9192
}

Cómo citar este artículo: Fernández-Soria, Juan Manuel y Diego Sevilla Merino. «La Ley General de Educación de 1970, ¿una ley para la modernización de España?». Historia y Memoria de la Educación 14 (2021): 23-68 
for the modernization of Spain. The defining feature of the Law was the ambition with which it sought to modernize the educational system; hence, we focus on the concept of "modernization" as well as its precedents and the modernizing axes contained in the Law. We also look at the socio-economic and political context that help to explain its creation. Given the law's importance, the article pays special attention to the obstacles and resistance that made its genesis and application so difficult, as well as the controversies that have arisen from the reform it promoted. Finally, by way of discussion, an assessment of the law is made taking into account the aspects that make up the concept of "modernization".

Keywords: School legislation; General Education Act of 1970; Modernization of the educational system; Education reform; Francoism and education.

\section{INTRODUCCIÓN}

Entre las razones que se invocan para explicar y justificar la oportunidad de la Ley General de Educación (LGE) se suele aceptar sin discusión la necesidad de modernizar el país. De forma explícita los impulsores de la Ley mencionan el apremio de modernizar España en sus estructuras económicas y sociales. Pero también cabe pensar, como han advertido numerosos estudios, que aquella modernización también estaba pensada para influir en otra, si no más, al menos tan importante, la política. Es posible sostener que el régimen franquista, necesitado de una nueva legitimidad, la buscó en la mejora de los balances económicos -que supuestamente no tienen ideología-, en el progreso social, en la eficacia. "Tecnopragmatismo» llamó a esto Manuel Ramírez. ${ }^{1}$

Y la educación fue convocada para este propósito. Sin modernizar el sistema educativo no sería posible el adelanto del sistema productivo, ni el perfeccionamiento social. Como en anteriores momentos de su historia, España se vuelve hacia Europa en busca de experiencias, otro tradicional signo de modernización. Pero sabemos bien que, en la persistente dialéctica progreso-regreso, todo intento de avance encuentra obstáculos y resistencias en quienes ven peligrar en el adelanto su situación de privilegio.

\footnotetext{
1 Manuel Ramírez, España 1939-1975 (Régimen político e ideología) (Barcelona: Labor, 1978), 55.
} 
Nos proponemos en este artículo examinar los factores que permiten hablar de una Ley para la modernización de España. Para ello exploramos el contexto socioeconómico y político de la Ley que nos ponga en situación de entender mejor la necesidad de modernizar el país. Para saber de qué hablamos cuando lo hacemos de «modernización» nos adentramos en el significado de este concepto para, partiendo de su contenido, describir los ejes modernizadores de la Ley, intuyendo que sus implicaciones provocan las resistencias y obstáculos a los que tuvo que enfrentarse no solo en su tiempo, sino también en el nuestro, como lo reflejan las controversias recientes habidas al calor de la Ley de la Memoria Histórica.

\section{EL CONTEXTO SOCIOECONÓMICO Y POLÍTICO DE LA LEY}

Como es sabido, la política es inseparable de su contexto, que la motiva, justifica y explica. Por eso, entender una ley de la trascendencia política de la LGE requiere considerar su contexto, al menos en sus principales dimensiones, es decir, el político, económico, social y cultural de los años 60 .

En el panorama del mundo occidental, habría que señalar que han pasado ya quince años -la convencional cifra con la que señalamos un cambio generacional- desde el término de la II Guerra Mundial. Ha crecido una nueva generación que quiere abrirse a formas de vida más libres, menos marcadas por grandes ideales y sacrificios, más reacia a asumir tradiciones y normas. En Estados Unidos destacan, sobre todo entre la juventud, la oposición a la Guerra del Vietnam y el apoyo al pacifismo; los grandes conciertos de música al aire libre para jóvenes tienen un efecto socializador en un ambiente de rechazo a las imposiciones y el deseo de un máximo de libertad; tienden a generalizarse la permisividad a las drogas y la fuerte influencia del movimiento hippy. Estas tendencias chocan además con la nefasta gestión de la Guerra del Vietnam y las extremas imposiciones del Comité de Actividades Antiamericanas, por lo que la suma de factores induciría a señalar el desarrollo de una contracultura. ${ }^{2}$ Por otro lado, hay que añadir la influencia de

\footnotetext{
2 «La contracultura no busca un nuevo sistema, es sólo la lucidez frente a los sistemas dominantes a través de la historia. Por eso será siempre alternativo y si se quiere, también a veces sumergido.»: José Luis Herrera Zavaleta, «Filosofía y contracultura», Quaderns de filosofia i ciencia 39 (2009): 79.
} 
una serie de personajes y hechos que aportan o apoyan esas nuevas formas e ideas. En Estados Unidos fueron muy significativos la elección del presidente Kennedy, la figura y acciones de Martin Luther King y del Movimiento de los Derechos Civiles; en Europa, Juan XXIII y el Concilio Vaticano II que impulsó en la Iglesia católica un aggiornamento, una actualización de su mensaje y su forma de estar presente en el mundo; en el bloque soviético, Alexander Dubcek y la primavera de Praga cuyo aplastamiento demostró que no era posible una evolución en los Estados controlados por la URSS; y el Mayo francés del 68, de escasa eficacia directa pero de enorme repercusión cultural. Estamos, por lo tanto, ante muchos impulsos hacia el cambio y lo nuevo en lugar de hacia el pasado y la tradición.

Es difícil, seguramente, negar las influencias que este contexto internacional ejercería en España, especialmente en los sectores que, pese al fuerte control que el Régimen mantenía en el país, estaban abiertos al exterior. Con todo, España era diferente, como decía el eslogan turístico de los años sesenta. Se daba una mayor distancia temporal al término del período bélico, pero en lugar de los beneficios del Plan Marshall se había soportado un bloqueo internacional y una aciaga política económica que imponía una absurda autarquía. La derrota de las potencias del Eje Roma-Berlín, sus aliadas, había llevado al franquismo la hostilidad y el menosprecio de los países promotores de la ONU. El Gobierno se sustentaba en una durísima represión que hacía de la paz la continuación de la guerra con otros medios; en el férreo control que se ejercía en todas las actividades; y en el recurso a una exaltación ideológica y mitificadora de España y el catolicismo. Sin embargo, en la década de los 50, una serie de acontecimientos facilitarían importantes cambios.

La muerte de Stalin en 1953 y el ascenso de Nikita Jrushchov permitió a Santiago Carrillo postular el abandono de la estrategia de derribo del franquismo por la violencia y promover una «reconciliación nacional». El 8 de agosto de 1953 se firmaba un Concordato entre la Santa Sede y el Estado español. Entre la Iglesia y la sublevación militar hubo desde el comienzo coincidencia de planteamientos e intereses y con este acuerdo de máximo nivel se facilitaba una mayor estabilidad y una

Ver también: Rafael Dezcallar, «Contracultura y tradición cultural», Revista de Estudios Políticos (Nueva Época) 37 (1984): 209-237. 
mejor regulación entre ambos. Gracias a él, Franco se garantizaba la continuidad de un fuerte apoyo ideológico y socializador y la Iglesia el sostén legal y económico para ejercer su misión. En tercer lugar, el 27 de agosto de ese mismo año se rubricaban tres «acuerdos ejecutivos» entre Estados Unidos y España. Franco era un dictador y su régimen tenía demasiado parecido con los derrotados en la II Guerra Mundial, pero era absolutamente anticomunista por lo que se convertía en un cómodo aliado para la Guerra Fría. Finalmente, el Régimen lograba su aceptación internacional con el ingreso de España en la ONU el 14 de diciembre de 1955.

La postración de la situación económica española obligó a Franco a aceptar el fracaso de la autarquía. Probablemente fue parte de un proceso más amplio en el que de la mano de su alter ego, el almirante Luis Carrero Blanco, se iniciaba la modernización tecnocrática del Régimen. Para ello se recurrió a dos personas profesionalmente muy cualificadas, miembros célibes del Opus Dei y de indudable identificación con el Régimen, Laureano López Rodó y Alberto Ullastres Calvo. Ambos contribuyeron decisivamente a introducir racionalidad y eficacia en la disfuncional administración franquista. El primero fue nombrado en 1956 secretario general técnico de la Presidencia de Gobierno y desde este puesto influiría decisivamente en la modernización de la administración; el segundo, nombrado ministro de Comercio en 1957, finiquitó la etapa autárquica y junto con Mariano Navarro Rubio organizó el Plan Nacional de Estabilización Económica de 1959 con el que se prepararía a la economía española para su despegue económico de los años sesenta.

No solo desde el Gobierno se iniciaba la modernización. En realidad, todo el país iba saliendo de la negra etapa del primer franquismo para cambiar en casi todos los sentidos. Se había ido produciendo una fuerte emigración del campo a las ciudades y de las zonas más atrasadas económicamente a las de mayor desarrollo; asimismo, aprovechando el fuerte crecimiento de la economía europea, en los años cincuenta y más aún en los sesenta, llegaron a emigrar en diferentes momentos más de dos millones y medio de personas. ${ }^{3}$ Estos movimientos liberan al país de una mano

\footnotetext{
3 Juan B. Vilar, «Las emigraciones españolas a Europa en el siglo XX: algunas cuestiones a debatir», Migraciones \& Exilios: Cuadernos de la Asociación para el estudio de los exilios y migraciones ibéricos contemporáneos 1 (2000): 131-159. file://C:/Users/diese/Downloads/Dialnet-LasEmigracionesEspanolasAEuropaEnElSigloXX-2328092\%20(2).pdf (consultado el 18-1-2021).
} 
de obra excedentaria a la vez que aportan divisas extranjeras que sirven para nivelar la balanza de pagos y adquirir patentes y maquinaria industrial.

La distribución de la población activa llevó a cabo una transformación impresionante. Si en 1950 el sector primario ocupaba el 49,3\%, el industrial el $24,8 \%$ y los servicios el $25,9 \%$, en 1960 los porcentajes eran el 40,2, el 30 y el 29,8 y en 1970 el 24,2 , el 37,8 y el 38,8, respectivamente. ${ }^{4}$ Es decir, en veinte años, el sector primario pasó de ocupar a casi la mitad de la población activa a menos de una cuarta parte, mientras que industria y servicios crecían hasta convertirse en mayoritarios.

El crecimiento del poder adquisitivo de millones de europeos y el atractivo del clima y las playas favoreció el rápido crecimiento del turismo. Se pasó del medio millón de turistas en 1950 a 6 millones en 1960 y 36 en 1970. ${ }^{5}$ Por lo tanto, en este período de tiempo, los turistas pasaron de ser algo anecdótico a suponer un número de visitantes casi equivalente a la población nacional. Comienza el desarrollo del que será uno de los sectores más importantes en la economía nacional y una de las principales fuentes de divisas. Pero el número tan elevado de turistas no solo tiene una traducción en términos económicos, también ejerce una importante influencia cultural. Su solvencia económica y su estilo de vida cuestionan gran parte de los valores y costumbres que el Régimen había tratado de imponer a través de la ideología del nacional-catolicismo.

Con la sustitución de la autarquía por la liberalización, la apertura al exterior y el saneamiento que supuso el plan de estabilización de 1959, se produce un fuerte crecimiento de la renta nacional. Así, si le concedemos a la misma un valor de 100 en 1950, en 1960 ascendería a 178 y en 1970 a 388; 6 se logran tasas anuales de crecimiento solo superadas en el mundo occidental por Japón y Grecia. Prácticamente, en veinte años, casi se había cuadruplicado la renta nacional. Esto permite al Régimen

\footnotetext{
4 Albert Carreras y Xavier Tafunell (coords.), Estadísticas históricas de España, ss. XIX y XX. Fundación BBVA. Segunda Edición. 2005, 100-105. https://www.fbbva.es/wp-content/uploads/2017/05/dat/ DE_2006_estadisticas_historicas.pdf (consultado el 18-1-2021).

5 Carmelo Pellejero Martínez, Evolución de los movimientos turísticos fronterizos y de las demandas hotelera y extrahotelera en España a lo largo del siglo XX: http://www.usc.es/estaticos/congresos/histec05/b15_pellejero.pdf (consultado el 18-1-2021).

6 Carreras y Tafunell (coords.), Estadísticas históricas de España, ss. XIX y XX, 1300 y siguientes.
} 
una fuente de legitimación muy diferente a la que había venido utilizando en los años cuarenta y parte de los cincuenta. Si entonces se recurría a una legitimación ideológica (el anticomunismo, la religión católica, la heroica "cruzada», hechos mitificados de la historia de España...), en los años sesenta se insistía más en el bienestar material que estaban garantizando los años de paz y trabajo bajo la autoridad de Franco.

Es fácil comprender la influencia que los cambios anteriores tenían en la escolarización. El incremento de la urbanización y el predominio de los sectores industrial y de servicios frente al sector primario hacía que las familias vieran en los estudios un medio de progreso y ascenso social y se tradujera en demandas de mayor y más continuada escolarización a la que a duras penas podía responder un sistema educativo pensado para otra sociedad. De hecho, las estadísticas nos indican que en 1950 estaba escolarizada el 51\% de la población de entre 5 y 17 años, en 1960 el $60 \%$ y en 1970 el $89 \% .^{7}$

Ante los fuertes cambios en población, economía y cultura, el contraste aparecía frente al inmovilismo político. Ciertamente ya no existían los niveles de encarcelamiento y represión que hubo desde el final de la Guerra hasta principios de los cincuenta, pero el Régimen seguía negando las libertades públicas y derechos fundamentales, y no aceptaba ningún tipo de representación democrática. Había disminuido el peso de los «azules» y crecido el de los tecnócratas caracterizados -contrariamente a los anteriores- por la racionalidad, el orden y la eficacia, pero a las movilizaciones cada vez más frecuentes de los obreros y los universitarios, la respuesta siempre terminaba en represión. Denota el grado de preocupación para los responsables políticos que suponía esa creciente contestación el hecho de su institucionalización con la creación del Tribunal de Orden Público (TOP). Se trató de un tribunal especializado y dedicado a imponer severas penas por acciones que serían absolutamente legales dentro de un sistema democrático. ${ }^{8}$ En este

\footnotetext{
7 Estíbaliz Ruiz de Azúa, «Un primer balance de la educación en España en el siglo XX», Cuadernos de Historia Contemporánea 22 (2000): 159-182.

8 Sara Núñez de Prado y Raúl Ramírez Ruiz, «La oposición al franquismo en las sentencias del TOP: Organizaciones políticas y movimientos sociales», Cuadernos de Historia Contemporánea 35 (2013): 263-285. El TOP sustituyó al Tribunal Especial de Represión de la Masonería y el Comunismo, recogiendo algunas de sus funciones.
} 
sentido, una vez más, quedaba clara la incapacidad del franquismo de evolucionar hacia la democracia.

\section{APROXIMACIÓN AL CONCEPTO «MODERNIZACIÓN»}

En el lenguaje común asociamos moderno a algo nuevo, actual, y lo contraponemos a lo antiguo, a lo que pertenece a otra época. La misma Real Academia lo recoge en este sentido y lo vincula al tiempo de la persona que habla o, al menos, al reciente. ${ }^{9}$

En las ciencias sociales, el término modernización suele usarse para definir el conjunto de las transformaciones sociales que implican la consecución de unos objetivos nuevos con efectos innovadores para una sociedad. ${ }^{10}$

Se trataría de superar atrasos en conocimientos, actitudes, instituciones, teorías, prácticas, que con el tiempo han quedado desfasadas o se viene comprobando que no son las mejores por lo menos en el presente. Hay que reconocer que, en cierto modo, se trata de un proceso general y hasta cierto punto inevitable, enraizado en tendencias evolutivas universales, que procede de predisposiciones profundas de los seres humanos.

Como se puede suponer, en este amplio proceso se suelen considerar aspectos, factores, características... Es importante el incremento de los conocimientos que aumenta la fe en la inteligencia y en la razón, así como una minusvaloración de la tradición. Suele afectar a las creencias religiosas que en algunos casos se abandonan y en otros se transforman. Lo sagrado y lo religioso se hacen más privados, y el Estado con sus instituciones se expande a ámbitos anteriormente ocupados por eclesiásticos y religiosos. La vida y las costumbres se regulan por saberes profanos como el Derecho y las ciencias sociales que se presentan como razonables y no se aceptan simplemente por criterios de autoridad o tradición.

\footnotetext{
9 Ver «moderno»: https://dle.rae.es/moderno?m=form.

10 Teresa Carnero, «Modernización Política: Una Propuesta de Aná1isis», Historia Contemporánea 4 (1990): 133-144.
} 
Tiene una gran influencia el desarrollo de las ciencias y sus aplicaciones prácticas, fundamentalmente industriales, que modifica la producción e incide en muchas profesiones. Muchos trabajadores y sus familias emigran del campo a las ciudades. La mayor demanda laboral de la industria y los servicios, así como la urbanización inciden en el incremento de la escolarización. Por lo tanto, aparecen nuevas funciones sociales, cambian y se perfeccionan otras que ya existían e incluso aparecen nuevas profesiones. En definitiva, surgen nuevas formas de trabajar, actuar, pensar e incluso vivir. La economía, lo material, ocupan los primeros puestos en las valoraciones de las personas y sociedades.

Ante estos cambios no todas las personas e instituciones actúan de la misma forma. Las hay que buscan intensificarlos, incrementarlos y acelerarlos mientras que otras se oponen, los obstaculizan o al menos los retardan. Es frecuente que quienes ocupen puestos de responsabilidad tiendan a lo segundo. Y, por supuesto, en estas circunstancias juegan un papel crucial personas con capacidad de liderazgo e idóneas para gestionar las tensiones que acompañan a estos cambios. Sobre todo, porque, como consecuencia de esta doble tendencia, se producen conflictos en la sociedad pues los grupos que ven rechazados sus deseos de cambio y mejoras no se resignan fácilmente y adoptan diversos modos de luchar por ellos. Lógicamente, los medios de comunicación social, así como los académicos, jugarán un papel diferente, especialmente frente a las élites políticas, que puede ser de subordinación, colaboración y ayuda a los grupos en el poder o, por el contrario, de oposición a ellos y apoyo a los cambios. ¿Qué hay de esto en el tiempo de la LGE?

En el tardofranquismo (1969-1975) es habitual encontrar entre los políticos proclamas autocomplacientes de «modernización». Afirmaciones que suelen reiterar los historiadores de ese período. Recordando los cincuenta años de la aprobación de la Ley General de Educación de 1970, recuperamos ese concepto. Pero surge apremiante la advertencia de Manuel Loff sobre la importancia de precisar los conceptos, sobre todo cuando los referimos a los regímenes totalitarios, dados a reputar de novedosa, progresista y moderna su política. Incluso se autocalifican de «nuevos»: «Nuevo Estado», «Nuevo Orden», «Nuevo Régimen»... Pero sabemos bien que, para estos regímenes, lo «nuevo» es aquello que les sustenta -como el rechazo a las ideologías «disolventes»-, y tienen por «modernas» las medidas encaminadas a lograr ese objetivo y las 
ideas «viejas» llamadas a rescatar al hombre de los extravíos del mundo moderno y protegerlos en el seno de la "modernidad» fascista. ${ }^{11}$ Se impone, pues, concretar el concepto «modernización» que guía nuestro acercamiento a la LGE.

Algunos, como el politólogo y teórico de la modernización política, Gianfranco Pasquino, ven un factor esencial para esta el tránsito de la condición de súbdito a la de ciudadano, categoría en la que incluye la expansión del derecho al voto y de la participación política, la adhesión a los principios de igualdad y la aceptación del valor de la ley igual para todos. Pero advierte que la modernización política es un proceso dinámico que no necesita "asumir como modelo formas políticas existentes»; y en este sentido afirma que no hay que confundir "modernidad con democraticidad».12 Quizá sea este el significado que le confiere Antonio Viñao al concepto modernización política, que reflejaría «aquellos procesos, estadios o etapas a través de las cuales se "modernizan" unas determinadas estructuras políticas», ya sea persiguiendo un modelo "predeterminado», ya sea emprendiendo un desarrollo continuado para llegar al anterior, en este caso un modelo democrático. ${ }^{13}$

La teoría de la modernización caracteriza este concepto señalando el tránsito de una sociedad tradicional estratificada socialmente, fuertemente rural, en la que la religión despliega una autoridad decisiva, a otra sociedad moderna que, distanciada de esas ataduras obstaculizadoras del desarrollo económico, adopta un proceso burocratizado, favorece el ascenso social, es permeable a la diferenciación política, asume la complejidad social y se basa en los procesos democráticos. En este tipo de sociedad el Estado asume un papel de liderazgo, protagoniza la educación como elemento de transformación social y económica, desempeña un papel determinante en la movilidad social, interviene en la planificación de la economía, etc.

\footnotetext{
11 Manuel Loff, «La política cultural de los «Estados nuevos» español y portugués (1936-1945): tradicionalismo, modernidad y confesionalización», Revista de Occidente 223 (1999): 55.

12 Gianfranco Pasquino, «Modernización», en Diccionario de Política, eds. Norberto Bobbio, Niccola Mateucci y Gianfranco Pasquino (México-Buenos Aires: Siglo XXI, 2005): I, 988.

13 Antonio Viñao, «La Ley General de Educación de 1970: ¿final de una etapa? ¿comienzo de otra?», en Modernización educativa y socialización política. Contenidos curriculares y manuales escolares en España durante el tardofranquismo y la transición democrática, ed. Manuel Ferraz Lorenzo (Barcelona: Ediciones Morata y Universidad de La laguna, 2020): 141.
} 
Podemos, entonces, señalar como principales rasgos de la modernización (noción que señala a los grandes procesos de cambio sociales, políticos y económicos) visibles en la LGE, el predominio de la autoridad racional en detrimento de la carismática y tradicional (Max Weber); la centralización estatal, propia del proceso de racionalización de las sociedades modernas; la expansión y progresiva secularización del Estado y su capacidad para dirigir los asuntos públicos; la diferenciación estructural y funcional de la esfera pública; la presencia de una sociedad diferenciada y cada vez más secularizada; la adhesión al principio de igualdad de todos ante la ley; el desarrollo de la participación política; la autonomía, emancipación y autosuficiencia del individuo, el acercamiento a Europa, signo secular de modernización en España.

Algunos de estos rasgos ya estaban presentes en nuestra historia educativa antes de la promulgación de la LGE.

\section{PRECEDENTES MODERNIZADORES DE LA LGE}

Ricardo Díez Hochleitner, en su «pequeña historia» de la LGE, sostiene algo en lo que hay unánime coincidencia: que ninguna reforma importante, como fue la de 1970, «es casual o espontánea, sino que responde a un complejo cúmulo de circunstancias que coadyuvan y conducen a la misma». ${ }^{14}$ Indudablemente, la LGE es resultado de un proceso histórico que, si para unos se sumerge en el mejor pasado conservador y liberal español, para otros lo hace en las inmediaciones de la década de 1960. Entre los primeros, Manuel de Puelles afirma que la ley incorpora principios tanto «del conservadurismo español más logrado»-el del regeneracionismo- (pragmatismo, europeización, modernización, neutralidad política, cientifismo, positivismo, pedagogismo), como del «mejor pasado liberal español», del que incorpora algunos principios del ideario pedagógico de la ILE. ${ }^{15}$ Y Félix Ortega afirma incluso que la reforma

\footnotetext{
14 Ricardo Díez Hochleitner, «La reforma educativa de 1970. Su pequeña historia», en Ministerio de Educación y Ciencia, Simposium internacional sobre Educación e Ilustración. Dos siglos de reformas en la enseñanza. Ponencias (Madrid: Centro de publicaciones-Secretaría General Técnica. Ministerio de Educación y Ciencia, 1988), 480.

15 Manuel de Puelles Benítez, «Tecnocracia y política en la reforma educativa de 1970», Revista de educación n. ${ }^{\circ}$ ext. "La Ley General de Educación veinte años después» (1992): 24 y 28. Hasta el extremo de que el preámbulo llega a reproducir casi literalmente párrafos completos del Real Decreto de 10 de mayo de 1918 que crea el Instituto-Escuela.
} 
vuelve «al pasado liberal y republicano» tan denostado (y perseguido) por el Nuevo Estado». ${ }^{16}$ Por su parte, Antonio Viñao remonta esos precedentes, al menos en determinados aspectos como la ruptura de la separación entre la primera y la segunda enseñanza, a la introducción en 1898 de la escuela graduada y su desarrollo posterior. ${ }^{17}$ Otros ponen el acento en los antecedentes más inmediatos de la década de los 60, escenario de experiencias y transformaciones decisivas que aportaron las condiciones necesarias para la reforma de 1970. Pero unos y otros convienen en que la LGE no nace de forma espontánea sino acrisolando influjos tanto lejanos como cercanos en el tiempo.

Indudablemente, no es posible entender la LGE sin los años que la preceden, sin lo acontecido en eso que algunos han llamado «transición corta»-finales de los 50 y década de los 60- que engarzaría con el «modo de educación tecnocrático de masas», previo abandono del modo de educación «tradicional elitista» propio de la «transición larga» (mediados del XIX-mediados del XX), que culmina en la LGE de 1970.18 En esa «transición corta» acontecen situaciones que reclaman una reforma de la enseñanza al tiempo que otros hechos la van fraguando. Como acabamos de ver, las circunstancias sociopolíticas y económicas fueron las idóneas para que se produjera esa reforma. España se abre, aunque tímidamente, al exterior, de donde empiezan a llegar inversiones y capitales financieros. El auge del turismo de masas, la aparición de nuevos movimientos culturales, el incremento de los sectores productivos secundario y de servicios en detrimento del primario, y el consiguiente proceso de urbanización, descubren la educación como elemento de mejora profesional y de ascensión social. La liberalización económica -que no política- empieza a ser una realidad, sobre todo a partir del Plan de Estabilización Económica de 1959, apoyado por el BM, la OCDE y el FMI, y el subsiguiente período de desarrollo. El incremento de las

\footnotetext{
16 Félix Ortega, «Las ideologías de la reforma educativa de 1970», Revista de Educación n. ${ }^{\circ}$ ext. «La Ley General de Educación veinte años después» (1992): 31.

17 Antonio Viñao, «El sistema educativo español: evolución histórica», en Procesos y contextos educativos: enseñar en las instituciones de educación secundaria, coord. F. Imbernon (Barcelona: Graó, 2010), 20.

18 Raimundo Cuesta, Juan Mainer y Julián Mateos (coords), «Modos de educación y problemas de periodización histórica desde una perspectiva genealógica», en Transiciones, cambios y periodizaciones en la Historia de la Educación, coords. R. Cuesta, J. Mainer y J. Mateos (Salamanca: autoedición, 2009), 31-32.
} 
huelgas laborales y las movilizaciones estudiantiles, que provocaron la crisis de gobierno de 1967 y el inicio del ministerio de Villar Palasí, facilitan el acercamiento al capitalismo occidental. El agotamiento político del régimen al que -siguiendo a Max Weber- ya no legitima como antes el carisma del caudillo ni los fundamentos de la tradición, encuentra un nuevo modelo de legitimación en la autoridad racional-legal, en la eficacia de las leyes (de 1958 data, por ejemplo, la Ley de Principios Fundamentales del Movimiento), en el bienestar (cuyo símbolo es el «seiscientos») que acarrean los elevados índices de productividad, y en el triunfo de la tecnocracia sobre la fingida desaparición de la ideología. Son todos ellos factores que alumbran la necesaria reforma de la enseñanza. Este es el terreno abonado que encuentran los organismos internacionales (OCDE, UNESCO, BM, FMI...), sus consultores y expertos, y países, como EEUU, interesados en irradiar las teorías de modernización y del capital humano, ${ }^{19}$ para sembrar en España sus ideas de desarrollo económico, social y educativo.

Tras ser aceptada en las instituciones internacionales, España acoge esas ideas, aunque a veces no sin resistencias. Su integración en programas como el Proyecto Regional Mediterráneo (PRM), no solo le hace ver el estancamiento, obsolescencia e inadaptación de su sistema educativo a las exigencias sociales y del sistema productivo, sino que también le ofrecen experiencias innovadoras, metodologías y diseños curriculares novedosos, y diferentes enfoques de la política educativa que España hace suyos. Tanto es así que, en palabras del entonces ministro de educación, Manuel Lora-Tamayo, las orientaciones del PRM estaban teniendo una «enorme influencia en la política educativa española», con la que guardaban un «extraordinario parecido»..$^{20}$ Los Planes de Desarrollo incorporan esas orientaciones bajo el liderazgo de un grupo de tecnócratas defensores de la productividad y la eficacia, y representantes de la

\footnotetext{
19 Esto ha sido investigado recientemente por Óscar J. Martin y Lorenzo Delgado Gómez-Escalonilla, «Educational Reform, Modernization and Development. A Cold War Transnational Process», en Teaching Modernization. Spanish and Latin American Educational Reform in the Cold War, eds. Ó. J. Martin y L. Delgado Gómez-Escalonilla (New York: Berghahn Books, 2020), 235-260.

20 Citado en Lorenzo Gómez-Escalonilla, «Educación para el desarrollo. OCDE, asistencia exterior y reforma de la enseñanza en la España tardofranquista», Foro de Educación 18, n. ${ }^{\circ} 2$ (2020): 137. Este autor afirma que «en cierta medida [el Libro Blanco] venía a ser una actualización de los análisis llevados a cabo en el PRM» asumiendo la vinculación entre educación y empleo («Educación para el desarrollo. OCDE», 142-143).
} 
apertura frente al inmovilismo. En esos Planes son visibles las recomendaciones de los informes de los organismos internacionales donde la educación aparece vinculada a la formación en capital humano en su consideración económica, lo que exigió sustituir la idea de gasto y consumo educativo por la de inversión, y la de improvisación por la de planificación. En un documento de la OCDE de 1963 sobre las necesidades educativas de España, se lee:

Es innegable que la educación es un bien de consumo desde el punto de vista del individuo, independientemente de su consideración como factor de crecimiento. Sin embargo, en nuestras circunstancias actuales se impone una planificación educativa que tenga perfectamente en cuenta las necesidades de mano de obra cualificada que el desarrollo económico implica. ${ }^{21}$

Estos informes, recogidos, como decimos, en los Planes de Desarrollo, son claros precursores de la orientación política que sigue el Libro Blanco y ratifica la LGE. Por eso el ministro Villar Palasí, en su discurso ante la Comisión de Educación de las Cortes, afirmó entonces lo que hoy todos reconocen: que la Ley recoge «las mejores experiencias internacionales»; lo que, por otra parte, restaría a la Ley algo del carácter de novedad con que la presentaba el ministro en ese mismo foro político cuando sostuvo que "la Reforma nace "ex novo" en nuestra Patria», aunque se ha acercado a donde estaban las

recomendaciones y soluciones más modernas, al tiempo que ha invitado a trabajar a los mejores especialistas del país y consultado siempre que fue necesario a las más destacadas figuras del mundo y a las más autorizadas organizaciones internacionales competentes en este campo, a las que España pertenece, como son la UNESCO, el Banco Mundial y la OCDE.22

\footnotetext{
21 Ministerio de Educación Nacional-OCDE, Las necesidades de la educación y el desarrollo económico-social de la España (Informe de la OCDE) (Madrid: MEC, 1963), 14.

22 José Luís Villar Palasí, «Discurso pronunciado por el Ministro de Educación y Ciencia, don José Luis Villar Palasí, al presentar ante la Comisión de Educación de las Cortes Españolas el proyecto de Ley General de Educación y de Financiamiento de la Reforma Educativa", Boletín Oficial de las Cortes Españolas. Diario de las Sesiones de Comisiones (BOCE.DSC.) Comisión de Educación y Ciencia, Apéndice n. ${ }^{\circ} 19$ (1 abril 1970), 3.
} 
Concretando más, algunos de los enunciados básicos de la LGE se originan años antes a partir de los informes internacionales, de los Planes de Desarrollo o de las propuestas del movimiento de enseñantes;23 así sucede, por ejemplo, con la obligatoriedad y gratuidad de la EGB, la extensión de la enseñanza obligatoria hasta los catorce años, ${ }^{24}$ la generalización del primer ciclo de la enseñanza secundaria (la segunda etapa de la EGB) instaurando la unificación de la enseñanza básica y rompiendo de este modo con el segregador sistema dual de la enseñanza, la sintonía del sistema educativo y el sistema productivo, la democratización -aunque cuantitativa- de la enseñanza media, la introducción en este grado de la Formación Profesional, la intensificación de la construcción de centros estatales a la búsqueda de un equilibrio con la enseñanza privada, la equiparación -al menos teórica- de las condiciones laborales de los profesores de la enseñanza pública y los de la enseñanza privada, la introducción de modelos curriculares habituales fuera de España-como la enseñanza programada- en un intento más, en opinión de Mariano González, «por modernizar el sistema educativo español en relación con los principales debates educativos que se produjeron en el ámbito internacional», ${ }^{25}$ etc. No debemos olvidar tampoco el antecedente que supuso la incorporación de la pedagogía funcionalista y experimental norteamericana a cuya difusión en España contribuyó decisivamente la revista Vida Escolar publicada por el Centro de Documentación y Orientación Didáctica de Enseñanza Primaria -CEDODEP-tras su creación en 1958, cuya «vitalización desde dentro del sistema escolar español» reconoce el Libro Blanco. ${ }^{26}$ Señala Agustín Escolano que los temas y los autores visibles en aquella revista constatan la presencia de la pedagogía

23 Sostiene Pérez Galán que los sectores tecnocráticos del régimen franquista reconocieron en el Libro Blanco las críticas que desde hacía años venían haciendo «extramuros del régimen» los docentes que militaban clandestinamente en partidos de izquierdas o que deseaban un sistema democrático, algunas de cuyas propuestas se recogen en la Ley (Mariano Pérez Galán, «La Ley General de Educación y el movimiento de enseñantes», Revista de Educación n. ${ }^{\circ}$ ext. «La Ley General de Educación veinte años después» (1992): 318-319.

${ }_{24}$ La universalidad hasta los 14 años ya había sido establecida por Ley de 29 abril 1964 (Boletín Oficial del Estado -BOE- 4 de mayo).

25 Mariano González-Delgado, «Las influencias internacionales en el sistema educativo español durante el tardofranquismo: una nueva visión historiográfica», en Ideas educativas en perspectiva filosófica e histórica. Circulación, recepción y concreción en la práctica, ed. Jon Igelmo Zaldívar (Salamanca: FahrenHouse, 2019), 75.

26 Ministerio de Educación y Ciencia, La educación en España. Bases para una política educativa (Madrid: Secretaría General Técnica del MEC, 1969), 56. 
funcionalista ya señalada que, asociada al positivismo didáctico, «intenta modernizar la vida escolar».27

En fin, concluyamos con Juan A. Lorenzo diciendo que «las principales cuestiones planteadas que relacionan los problemas sociales, económicos, etc., con los educativos, que fueron considerados en estos años de la década del sesenta, terminarían consolidándose en la Ley General de Educación», lo que confirma que el Libro Blanco y la LGE «no fueron fruto de la improvisación, sino que tuvieron unos precedentes [...] que los hicieron posibles», ${ }^{28}$ y sin los cuales no se podría comprender lo que supuso esa Ley para la modernización del país.

\section{LOS EJES MODERNIZADORES DE LA LEY}

Más arriba intentábamos concretar el concepto «modernización» enunciando algunos de sus rasgos básicos; entre ellos el predominio de la autoridad racional, la presencia de una sociedad diferenciada, la adhesión al principio de igualdad ante la ley, el desarrollo de la participación política, la autonomía del individuo, el acercamiento a Europa, y el protagonismo del Estado en los asuntos públicos. Creemos que, al menos en sus enunciados programáticos, la Ley de 1970 contempló estos rasgos modernizadores en su afán por transformar la sociedad española en una sociedad moderna.

Efectivamente, iniciábamos nuestra aproximación al concepto «modernización» señalando su contraposición a lo antiguo, a lo que tiene de transformación social y de superación de atrasos en varios ámbitos de la vida. Lógicamente, ese es el punto de arranque de la reforma de 1970. Transformar la sociedad española adecuándola al signo de los tiempos se convirtió en su razón de ser. Por eso el Libro Blanco menciona, con explícita intención demoledora, los principios básicos de la Ley Moyano -reflejo de otro tipo de sociedad- en los que permanecía anclado el sistema educativo español. Por eso también este documento de bases analiza, en un inusual autoexamen crítico, el sistema educativo heredado de aquella

\footnotetext{
27 Agustín Escolano Benito, «Discurso ideológico, modernización técnica y pedagogía crítica durante el franquismo», Historia de la Educación 8 (1989): 13.

28 Juan Antonio Lorenzo Vicente, «Los "precedentes" del Libro Banco y de la Ley General de Educación, con especial referencia a la educación secundaria», Revista de Educación 316 (1998): 367.
} 
sociedad, al que no repara en calificar de anticuado, desarticulado en sus diferentes niveles e injustamente discriminador. Para lograrlo, propone, con un notable discurso moderno, decisivas innovaciones pedagógicas y curriculares, a las que ya aludimos más arriba y que Alejandro Mayordomo analiza en su colaboración en este mismo número a la que remitimos.

Pero la Ley tiene otros ejes modernizadores, empezando por eso de lo que la propia Ley es signo y símbolo: el predominio de la autoridad racional en detrimento de la carismática y tradicional, que apuesta por ajustar la educación al desarrollo económico haciendo suya la teoría de la modernización que habla de eficacia, productividad y adaptación a las exigencias económicas y sociales del país; racionalidad que valora el capital humano como la auténtica riqueza de la nación y que tiene como la más rentable inversión la educativa, como defendió el ministro en su alocución televisada en enero de 1970 con motivo de la proclamación por la ONU de ese año como Año Internacional de la Educación. ${ }^{29}$ Adecuar la estructura educativa a la estructura ocupacional es, pues, como ya sabemos, un eje primordial de la Ley en su objetivo de acomodar la educación a la sociedad del momento. La importancia de este eje capital de la reforma, expresada a menudo sin ambages, no obstante, aconseja a los autores de la reforma desmarcarla de los planteamientos materialistas y del peligro de la deshumanización de la técnica, apercibidos como estaban de las resistencias que ahí podría encontrar la Ley. Casi desde el mismo momento de su gestación, salen al paso del «carácter aparentemente materialista» de ese planteamiento argumentando -ya en octubre de 1967- que responde a un concepto de desarrollo amparado por el Papa Pablo VI; ${ }^{30}$ defensa que reiteran más adelante señalando los valores humanistas en los que se enraíza la Ley y su comunión con la doctrina social y cristiana de la Iglesia. ${ }^{31}$

\footnotetext{
29 José Luis Villar Palasí, «España y el “Año Internacional de la Educación”. Alocución del excelentísimo señor don José Luis Villar Palasí, ministro de Educación y Ciencia, a través de Televisión Española, el día 16 de enero de 1970», Revista de Educación 206 (1969): 47.

30 Ricardo Díez Hochleitner, «Conferencia pronunciada por Don Ricardo Díez Hochleitner en el acto de apertura del IV Congreso Nacional de Pedagogía» (Pamplona, octubre, 1967), Revista de Educación 201 (1969): 67.

31 Ricardo Díez Hochleitner, «Palabras del Señor Ricardo Díez Hochleitner en la clausura del Seminario Internacional sobre Prospectiva de la Educación», Revista de Educación 215 (1971): 125, y Villar Palasí, "Discurso ante la Comisión»: 37 y 41-42, BOCE.DSC. Comisión de Educación y Ciencia, Apéndice n. ${ }^{\circ} 19$ (1 abril 1970): 4.
} 
Pero la adecuación del sistema educativo al sistema productivo tiene otro propósito: el de atender a un futuro en constante proceso de cambio; un futuro que se quiere -se exige- más justo y participativo y que requiere planteamientos de prospección y planificación educativa, tan apreciados por los tecnócratas del Régimen, especialmente Díez Hochleitner, ${ }^{32}$ y reconocidos por el propio ministro. ${ }^{33}$

En efecto, la Ley ambiciona responder a las exigencias de una sociedad cada día más dinámica, radicalmente distinta a la sociedad estratificada y sin apenas movilidad social que pretende transformar. Y espera conseguirlo formando a hombres y mujeres para que no sean, en palabras del ministro en las Cortes, «la servidumbre» de los privilegiados, los «camareros o los limpiabotas» de los ricos, y para no condenar a España «a ser la gran suministradora de peones a toda Europa». ${ }^{34}$ En una sociedad moderna, sus gentes deben tener la posibilidad de mejorar y ascender socialmente según sus capacidades, e impedir que la desigualdad económica o "intereses egoístas de clase» ${ }^{35}$ los ancle definitivamente en su condición social de origen. La Ley de 1970 reconoce en su preámbulo que viene a modificar el «hermético» anterior sistema educativo propio de una «sociedad estática», haciendo de la educación, como quiere el Libro Blanco, un «medio de movilidad y ascensión económica, social y cultural», ${ }^{36}$ respondiendo así, como declaró el ministro en el Pleno de las Cortes, a la creciente demanda

32 Díez Hochleitner organizó varios cursos al respecto, como el Seminario sobre Planeamiento Integral de la Educación, auspiciado por el MEC, cuyo documento final anticipa algunos aspectos del Libro Blanco de 1969 (Ministerio de Educación Nacional, La educación y el desarrollo económico-social. Planeamiento integral de la educación. Objetivo de España para 1970. Curso-Coloquio sobre planeamiento integral de la educación (Madrid: Ministerio de Educación y Ciencia, 1962).

33 «La Ley General de Educación constituye un supuesto más de planteamiento prospectivo [...] Constituye un ejemplo expresivo de cómo la acción política se encuentra catapultada hacia el futuro de forma inevitable» (José Luis Villar Palasí, «Discurso del Ministro de Educación y Ciencia en la sesión inaugural del Seminario Internacional sobre Prospectiva de la Educación», Revista de Educación 215 (1971): 120).

34 Villar Palasí, «Discurso ante la Comisión de Educación de las Cortes», BOCE. DSC. Comisión de Educación y Ciencia, Apéndice n. ${ }^{\circ} 19$ (1 abril 1970): 7. Esta idea y conceptos se repiten más tarde en el «Discurso del ministro de Educación y Ciencia ante el Pleno de las Cortes en defensa del Proyecto de Ley General de Educación y Financiamiento de la de la Reforma educativa», BOCE. Diario de las Sesiones del Pleno, n. ${ }^{\circ} 2$ (28 julio 1970): 31.

35 Villar Palasí, «Discurso del ministro ante el Pleno de las Cortes», 30.

36 Ministerio de Educación y Ciencia, La educación en España, 204. 
social de educación que ve en ella «el único camino de auténtica promoción social». ${ }^{37}$

La prescripción para este fundamental eje es acabar con la injusticia en educación «haciendo desaparecer toda barrera discriminatoria posible, y, muy en particular, la que tuviese su origen en diferencias económicas o sociales». ${ }^{38}$ La voluntad estaba clara: posibilitar la igualdad de oportunidades en el acceso de todos a la educación, favoreciendo la consecución de una sociedad más justa. Sin duda era este un lenguaje nuevo en el Régimen. La universalidad y gratuidad de la Educación General Básica hasta los 14 años y la adopción de un sistema comprensivo eliminando las dos ramas de la enseñanza primaria precozmente diferenciadas y, por eso mismo, clasistas, son sendos ejes modernizadores esenciales de la reforma, consustanciales al derecho a la educación y a la igualdad de oportunidades que quiere impulsar el Libro Blanco y que no solo propician la mejora personal, sino que favorecen también la convivencia y la integración social. Estos son los instrumentos fundamentales de la «revolución silente y pacífica» de la que habla el ministro, "más eficaz y profunda que cualquiera otra para conseguir una sociedad más justa». ${ }^{39}$

La Ley acoge otro eje modernizador de gran calado: la participación social y política. El Libro Blanco reconoce que la evolución política española tiende hacia «una mayor participación ciudadana en los procesos de la vida política, social, económica y cultural del país», tendencia que, para su manifestación, debe ir acompañada de la formación que dote a la ciudadanía de competencia y responsabilidad en esos ámbitos. ${ }^{40} \mathrm{El}$ futuro de esa propensión no solo reside en la mejor adaptación del sistema educativo al desarrollo económico y social, sino también en su transformación democrática, sobre todo en su base. Reiteran los autores de la reforma que esa democratización redundará tanto en un beneficio personal como social, este en forma de mayor capacitación técnica, de ejercicio responsable de la libertad, de convivencia e integración

\footnotetext{
37 Villar Palasí, «Discurso del ministro ante el Pleno de las Cortes», 31.

38 Villar Palasí, «Discurso del ministro ante el Pleno de las Cortes», 32.

39 José Luis Villar Palasí, «Introducción» a Ministerio de Educación y Ciencia, La educación en España. Bases para una política educativa. (Madrid: MEC, 1969), 7.
}

40 Ministerio de Educación y Ciencia, La educación en España, 204-205. 
social que, ya desde la escuela, impida la amenaza de la división. ${ }^{41}$ Quizá como muestra de esta tendencia participativa el ministro quiere enfatizar el «amplio debate público» que precedió a la Ley, la participación en su elaboración, ${ }^{42}$ "consustancial a la reforma misma», y convocar a la participación de todos en el desarrollo de la Ley, porque si es para todos «tiene que ser una obra de todos». ${ }^{43} \mathrm{Y}$ a este propósito obedece la composición del Consejo Nacional de Educación que incluye las representaciones de los padres de familia, profesores, centros de enseñanza, Colegios Profesionales, de la Iglesia y de la Organización Sindical, la creación, con los mismos criterios de participación social, de las Juntas Provinciales de Educación, las Juntas de Distrito y la Juntas Comarcales, y la institución de otros cauces de participación social en la enseñanza (Comisiones, Asociaciones, Patronatos...), medidas que, en palabras del ministro ante la Comisión de Enseñanza de las Cortes, muestran «bien a las claras» la voluntad del Ministerio de «abrir nuevos cauces, realmente sin precedentes, de una efectiva participación de toda la sociedad en las tareas de la reforma educativa».44

La democratización de la reforma de 1970 tiene también, como anunciábamos hace un momento, beneficios personales concretados en la autonomía del individuo que se muestra en la reforma de 1970 y que interpretamos como otro de sus ejes modernizadores, en la medida en que busca la autosuficiencia personal, una actitud de emancipación propia de la modernidad opuesta a la servidumbre. El Libro Blanco, acorde con sus propósitos de prospección educativa, ve al futuro ciudadano inmerso en una sociedad en la que se desarrollan los medios de comunicación e información y se hace inevitable la vida masificada y la participación política; en consecuencia, en su parte propositiva, plantea no

\footnotetext{
41 Villar Palasí, «Discurso ante la Comisión de Educación», BOCE. DSC. Comisión de Educación y Ciencia, Apéndice n. ${ }^{\circ} 19$ (1 de abril de 1970): 8.

42 Villar Palasí, «Discurso ante la Comisión», 3. Fue la participación un «obsesivo concepto» para el ministro, que reitera varias veces en su discurso ante el Pleno de las Cortes de 28 de julio (Villar Palasí, «Discurso ante el Pleno de las Cortes»: 30). Antonio Viñao niega que hubiera más participación en el debate que la representada por los informes de las organizaciones y corporaciones permitidas por el régimen: entre ellas, el Instituto de Estudios Políticos, afín al Movimiento, y la Comisión Episcopal de Enseñanza (Antonio Viñao, Escuela para todos y modernidad en la España del siglo XX (Madrid: Marcial Pons, 2004), 82).

43 Villar Palasí, «Discurso ante el Pleno de las Cortes», 31.

44 Villar Palasí, «Discurso por el que se informa a la Comisión de Educación», 73.
} 
descuidar la capacidad crítica y la singularidad del individuo y prepararlo no solo para poder enfrentarse a esos cambios sociales, culturales y políticos, sino también para asumir «con mayor plenitud la libertad y la dignidad que como persona le corresponden y los derechos y deberes para con el bien común que a ellas van indisolublemente unidos». ${ }^{45} \mathrm{~A}$ las puertas de la aprobación de la Ley, y ante el Pleno de las Cortes, el ministro insiste en

la necesidad de capacitar críticamente al hombre para que pueda dar una respuesta humanista y personal a este aluvión de incitaciones y mensajes, a esta cosmogonía de información y para que la transmisión de la cultura al pueblo, en otros tiempos celosamente guardada como patrimonio exclusivo de círculos minoritarios y burgueses, sea una realidad conscientemente asumida. ${ }^{46}$

Europa marcaba la dirección en ese sentido, y en ella ve España, una vez más, la vía de solución a estos problemas. De modo que el acercamiento a Europa, a Estados Unidos y a instituciones internacionales como la UNESCO, el Banco Mundial o la OCDE, se erige en el que quizá sea uno de sus ejes modernizadores más unánimemente resaltados. En páginas atrás dábamos cuenta del reconocimiento de sus principales protagonistas a las destacadas figuras e instituciones cuya influencia es visible en la reforma de 1970. En muchos aspectos el Libro Blanco recoge su doctrina, a veces casi literalmente reconocible. No en vano uno de sus principales redactores fue José Blat Gimeno, eficaz funcionario de la UNESCO. Así, hay resabios de la doctrina de la UNESCO en la consideración de la educación como derecho primario habilitador que condiciona el ejercicio de los demás derechos, en la alusión a la educación como derecho de las personas, y no solo de los niños, en los postulados de la gratuidad que contempla el documento de bases, en el entendimiento de la aportación de la educación al bien común, etc. ${ }^{47}$ Nos eximen de una mayor profundización en este eje de la reforma los estudios que en este número presentan Mariano González-Delgado y Tamar Groves y Lorenzo Delgado Gómez-Escalonilla y Óscar Martín. No obstante,

\footnotetext{
45 Ministerio de Educación y Ciencia, La educación en España, 205.

46 Villar Palasí, «Discurso ante el Pleno de las Cortes», 31.

47 Ministerio de Educación y Ciencia, La educación en España, 143-145.
} 
sí queremos destacar, además del reconocimiento institucional de esas influencias, el contrapeso señalado por los mismos responsables de la Ley insistente en destacar su "cepa típicamente española», 48 en un nuevo intento de adelantarse a las previsibles críticas de extranjerizante y materialista que recibiría la Ley.

Pero ninguno de los ejes modernizadores mencionados sería posible sin el protagonismo del Estado en la reforma. Sabedor de esta exigencia, el legislador introdujo en el artículo 3.1. de la Ley la consideración de la educación «a todos los efectos» como un «servicio público fundamental». Eso equivalía a considerar como subsidiaria a la enseñanza privada y otorgar al Estado la iniciativa absoluta, como reconoció diez años después el ministro: "La primera tarea del Estado era que cada niño tuviera su plaza, y su plaza en la escuela más próxima. Y eso solamente podía hacerlo el Estado». ${ }^{49}$ Ya el Libro Blanco señalaba que "la creación de centros privados se ha hecho sin una cuidadosa planificación en conexión con la creación de Centros estatales», especificando que los centros privados no solían establecerse en función de la demanda sino donde "podían sostenerse mejor económicamente».50 Poco más tarde, cuando el ministro informa a la Comisión de Educación de las Cortes sobre la aplicación de la Ley, ${ }^{51}$ tiene que justificar la creación «sin precedentes» de miles de puestos escolares para EGB y Bachillerato no como una medida que encierre «una supuesta voluntad estatalizadora» como algunos han querido ver, sino como «la firme voluntad del Gobierno de asegurar el derecho a la enseñanza» derivada de la concepción de la educación como servicio público fundamental. La política de expansión escolar emprendida por el Gobierno no es signo de «estatismo», ni pretende «invadir ninguna iniciativa privada», sino que es consecuencia de la obligación que la Ley impone al Gobierno, y este

\footnotetext{
48 Villar Palasí, «Discurso ante el Pleno», 33.

49 Cuadernos de Pedagogía, «Villar Palasí, diez años después. Entrevista realizada a José Luis Villar Palasí, diez años después de la implantación de la Ley General de Educación de 1970. Valoración de la aplicación de la citada ley y exposición de las ideas que subyacen tras la misma». Cuadernos de Pedagogía 65 (1980): 25.

50 Ministerio de Educación y Ciencia, La educación en España, 58.

51 José Luís Villar Palasí, «Discurso del ministro de Educación y Ciencia por el que se informa a la Comisión de Educación de las Cortes sobre la aplicación de la Ley General de Educación y Financiamiento de la Reforma Educativa», BOCE. DSC. Comisión de Educación y Ciencia, Apéndice 10 (14 de febrero de 1972): 13.
} 
mandato «no es ninguna amenaza para nadie que no quiera especular con el déficit de puestos escolares». El ministro insiste en que «esta reforma no se ha hecho "contra nadie", sino para todos y, a ser posible, por todos», y que el Estado «no puede, no quiere» monopolizar la educación; de hecho, reafirma la libertad de elegir centro docente y recuer$\mathrm{da}$-con palabras que no debieron agradar a quienes quiso tranquilizarque la reforma reconoce a la Iglesia y otras instituciones «la posibilidad de ser concesionarios de centros docentes estatales». Las instituciones privadas y, particularmente la Iglesia, deseaban otra cosa: la subsidiariedad del Estado. Esta cuestión esencial fue motivo de «tensiones y desconfianzas» que el propio ministro reconoce, y que se sumaron a otras que obstaculizaron la reforma, como luego se verá. Pero el ministro tuvo clara -insistimos en que, al menos, de forma programática- la necesidad de la presencia activa del Estado en la reforma. Presencia que se manifestó también en la reorganización de la Administración educativa central y periférica, basada en criterios de funcionalidad, unidad de dirección, coordinación y desconcentración, y en la regulación de la Inspección como órgano de estímulo del profesorado y de control pedagógico. Que en su redactado final la Ley no contemplara el diagnóstico del Libro Blanco y suprimiera de hecho el Cuerpo de Directores -al que se accedía por oposición-, no hace sino abonar la tesis del control del Estado sobre una figura, la del director escolar, al que, dado el caso, podía remover, quizá también para favorecer medidas de actualización profesional y de innovación pedagógica que el planteamiento de la reforma requería. ${ }^{52}$

Como sabemos, estos ejes modernizadores encontraron resistencias, por un lado, entre sectores que los consideraron demasiado rupturistas con el pasado y, por otro, entre quienes los juzgaron insuficientes para las expectativas creadas o una nueva forma de legitimación de un régimen políticamente agotado.

\footnotetext{
52 Recientemente hemos conocido la oposición a esta medida de José Blat Gimeno quien no logró para este Cuerpo lo que sí consiguió para la Inspección. Al cabo de los años se lamentaba de esa medida «que la experiencia ha demostrado ulteriormente cuán desafortunada fue» (Amparo Blat Gimeno, «El Llibre Blanc i la Lley General d’ Educació de 1970 segons José Blat Gimeno», Educació i Història. Revista d' Història de l' Educació 36 (2020): 172). La colaboración de Aurelio González Bertolín y Roberto Sanz Ponce en este monográfico profundiza en esta cuestión.
} 


\section{OBSTÁCULOS Y RESISTENCIAS A LA LEY}

Es hasta lógico que ante la gestación de una política -y no hace falta decir que una ley es un instrumento para ella- surjan obstáculos y resistencias. Su significado, sentido, ideas, objetivos y hasta sus protagonistas están llamados a ser objeto de controversia. Con todo, llama la atención la cantidad e intensidad de la oposición que encontró la LGE.

Brevemente repasaremos la que plantearon los sectores del Régimen opuestos a la misma y que afectaron a su financiación; la que protagonizó la que había sido su gran aliada, la Iglesia; la que provenía de quienes debían aplicarla; y la de quienes abiertamente estaban decididos a oponerse a las acciones de la dictadura franquista.

Si, en primer lugar, nos detenemos en la oposición dentro del Régimen, reconoceremos que se comprenden los motivos que hubo para ella pues era evidente su manifiesto contraste respecto a los que habían sido sus planteamientos más propios en esta materia. Recordémoslo, la Ley iba a nacer dentro de un régimen autoritario, integrista, reaccionario y no para servirle dócilmente sino con la pretensión de promover un gran cambio, «una revolución silente y pacífica», pero revolución, que propiciara la modernización del país. Lo que pretendía era llevar a cabo un cambio total en un sistema educativo que, en sus líneas fundamentales, permanecía básicamente inalterado desde hacía más de cien años. Además, el cambio iba a ir en dirección opuesta a las ideas más genuinas del Régimen en educación. Si a pesar de ello siguió adelante, seguramente se debió a que era vista como una condición o, al menos un gran apoyo, al crecimiento económico, y este era valorado como un fuerte elemento legitimador y un necesario sostén al franquismo en aquellos años.

Por lo tanto, tenía sentido que sus propuestas provocasen la oposición de los sectores que detentaban un indudable poder dentro del Régimen («azules», altos cargos militares, tradicionalistas y algunos sectores de la Iglesia). Probablemente, también levantaría suspicacias tanto en Franco como en Carrero Blanco y no sería extraño que vieran con buenos ojos cuanto contribuyese a su debilitamiento. Era el precio a pagar por un equipo ministerial que no había ocultado sus intenciones, sino que se estrenó con un Libro Blanco en el que resaltaba sin piedad todos 
los defectos e injusticias del sistema educativo con el que el Régimen se identificaba desde hacía más de treinta años.

En efecto, si comparamos las ideas que inspiran la LGE con las de las primeras leyes educativas franquistas, nos extrañará cómo un mismo régimen pudo promover educaciones tan distintas. Recordemos que en el preámbulo de la Ley del 70 encontramos muchos de los ejes modernizadores ya descritos: el derecho de toda persona a la educación y su correspondiente consideración de servicio público, la democratización de la enseñanza, la necesidad de adaptación a un mundo en cambio acelerado, la búsqueda del consenso social ya que no se trataba de «vencer sino de convencer», la facilitación de la participación de toda la sociedad, la eliminación de cualquier discriminación, la planificación... En cambio, si acudimos a las leyes educativas iniciales del franquismo, aquellas que nos permiten apreciar sus ideas e intenciones más propias, notaremos que están en las antípodas de estos propósitos.

El Régimen mostró con rotundidad sus prioridades en educación. La primera ley promulgada, en 1938, todavía en plena contienda, tuvo por objeto a la segunda enseñanza y con un marcado sentido elitista: "la formación intelectual y moral de sus futuras clases directoras». Además, intentaba vincularse al pasado, el siglo XVI, «la época imperial». ${ }^{53} \mathrm{La}$ segunda ley educativa del franquismo estuvo dedicada a la Universidad. ${ }^{54}$ Basta leer su preámbulo para asombrarse de su fraseología hueca y rotunda en contraste con la penosa situación en que se encontraban sus aulas, controladas por la Falange y muertos o exiliados muchos de sus mejores profesores. Finalmente, la ley de enseñanza primaria quería conceder a la Iglesia las más amplias prerrogativas en este sector y convertir la escuela en un lugar de adoctrinamiento católico. ${ }^{55}$ No cabe, por tanto, extrañarse de que en quienes se identificaban con el Régimen naciera animadversión hacia una Ley que debían considerar ajena y hasta opuesta a sus ideales e intereses.

\footnotetext{
53 Ley de 20 de septiembre de 1938, de la Reforma de la Segunda Enseñanza (BOE, 23 de septiembre de1938).

54 Ley de 29 de julio de 1943, sobre la ordenación de la Universidad española (BOE, 31 de julio de 1943).

55 Ley de 17 de julio de 1945 sobre enseñanza primaria (BOE, 18 de julio de 1945).
} 
Ciertamente, con el tiempo, había aminorado el delirio ideológico de las primeras leyes. Los ministerios de Ruiz-Giménez (1951-1956), Rubio García-Mina (1956-1962) y Lora-Tamayo (1962-1968) actuaron ante los problemas educativos con más realismo y plantearon políticas más acordes con las necesidades de la educación y menos dependientes de los sesgos ideológicos del Régimen. ${ }^{56}$ Con todo, nunca se habían reconocido y abordado los problemas tan abierta, libre y directamente como se hacía en el Libro Blanco. Y menos firmado por un ministro.

A ello había que añadir las fuertes tensiones que dentro del franquismo existían en aquellos años entre los llamados «azules» y los «tecnócratas». Pensando en la retórica falangista y sus frecuentes alusiones a «la revolución pendiente», a «la patria, el pan y la justicia», se habría podido imaginar una cierta conexión con algunos de los objetivos políticos de la Ley. Sin embargo, esta hipotética conexión desaparecía en cuanto se constata la vinculación o, al menos, proximidad del ministro al sector tecnócrata y la de sus colaboradores a organismos internacionales. ${ }^{57}$ Por lo tanto, los «azules» no necesitaban esforzarse para encontrar motivos más que sobrados para la oposición.

Y esta se desarrolló de una forma relativamente discreta -no tenía sentido airear confrontaciones internas-, pero con suma eficacia pues yuguló algo tan necesario como su financiación. Llama la atención que el proyecto de la LGE tuviera que pasar por tres comisiones de las Cortes. A su lógica tramitación por la de Educación, se añadieron la de Presupuestos y la de Hacienda. Y si, durante los meses de abril, mayo y junio de 1970, la comisión de Educación se enredó en prolijas discusiones que al final no cambiaron nada sustancial del Proyecto, fueron bastantes dos días para que las de Presupuestos y Hacienda negaran la garantía de una suficiente financiación a la futura Ley. Villar Palasí había cuidado de modo especial el tema pues era consciente de la importancia que iba a tener para su

\footnotetext{
56 Agustín Escolano Benito, «Los comienzos de la modernización pedagógica en el franquismo: (1951-1964)», Revista española de pedagogía 192 (1992): 289-310.

57 José Luis Villar Palasí llegaba al Ministerio de Educación procedente del de Comercio donde ocupó la Subsecretaría y en su equipo ocupaban cargos relevantes dos altos funcionarios de la UNESCO, Ricardo Díez Hochleitner como subsecretario y José Blat Gimeno como vicesecretario general técnico. Contar con personas que procedían de puestos relevantes en organismos educativos internacionales debería interpretarse como algo positivo. Sin embargo, recordemos que para las personas reaccionarias se veía como «una fuente de perniciosas influencias extranjerizantes».
} 
eficacia. ${ }^{58}$ De hecho, quiso que apareciera ya en su misma denominación completa. El día 1 de julio de 1970 se reunió la Comisión de Presupuestos y el 2, la de Hacienda..$^{59}$ A pesar de los esfuerzos de los dos ponentes, Federico Mayor Zaragoza y Ricardo Díaz Hochleitner, se aprobó quitar las disposiciones de la Ley que, ante la elevada inflación, prescribían mantener constante el valor de las inversiones consignadas. Se argumentó que no cabían imposiciones desde Educación a Hacienda, y menos durante los diez años que se preveían para su aplicación, y que no tenía sentido dudar de que el Gobierno atendería debidamente la adecuada financiación de la Ley. Concretamente, en la de Hacienda, Cruz Martínez Esteruelas, un destacado miembro del grupo «azul», 60 intervino al comienzo:

[...] a mí, desde un punto de vista técnico, me resulta inconveniente e inconcebible que, con ocasión de una reforma de la acción del Estado en un ramo se haga un planteamiento recaudatorio suscitando la petición de la reforma del sistema fiscal. Inducir al Gobierno a que realice una reforma tributaria finalista, me parece totalmente absurdo. ${ }^{61}$

A su intervención, como si se tratase de un plan previamente acordado, le siguieron otras que cerraban filas en su apoyo. Aparentemente, no se oponían a la Ley, sino que únicamente buscaban mejoras técnicas.

En segundo lugar, conviene reseñar la actitud y actividad de la Iglesia en relación a una Ley referida a una materia tan importante para ella como la educación. El artículo de Isabel Grana en este mismo monográfico las estudia adecuadamente por lo que aquí nos referiremos a esta cuestión de forma escueta.

La Iglesia y los sublevados, por sus características intrínsecas estaban llamados a ser aliados. Además, el laicismo de la II República y la

\footnotetext{
58 Fernando Serrano Pelegrí, «La tramitación de la Ley General de Educación y Financiamiento del Sistema Educativo de 1970. Análisis desde una perspectiva político-educativa» (Tesis doctoral, Universidad CEU - Cardenal Herrera, 2016): 276.

59 BOCE. DSC. Comisión de Presupuestos, Apéndice n. ${ }^{\circ} 84$ (1 de julio de 1970).

60 La adscripción de Cruz Martínez Esteruelas no presenta dudas. En 1965 había sido nombrado delegado nacional-jefe de la asesoría jurídica de la Secretaría General del Movimiento y en 1968 pasó a ocupar el cargo de delegado nacional de Asociaciones del Movimiento. Desde 1971 y hasta su nombramiento como ministro, precisamente, de Educación Nacional, fue secretario primero del Consejo Nacional del Movimiento.
}

61 BOCE. DSC. Comisión de Hacienda, Apéndice 85 (2 de julio de 1970): 3. 
persecución religiosa que se operó en la zona republicana durante los primeros meses de la Guerra intensificó al máximo esta alianza hasta parecer una aleación: el nacional-catolicismo. Sin embargo, la reforma educativa de los 70 estaba llamada a ponerla a prueba.

Sucedía, además, que la Iglesia en los años 60 estaba experimentando fuertes cambios. El Papa Juan XXIII y el Concilio Vaticano II habían impulsado una actualización que suponía notables disonancias con un franquismo mucho más inmovilista. Por ello, la parte de la Iglesia española más identificada con dicha actualización empezaba a sentirse incómoda con las relaciones privilegiadas con los poderes públicos que habían sido habituales desde la sublevación militar. Sin embargo, muy mayoritariamente no se quería renunciar a su fuerte presencia en la educación tal como estaba asegurada por el Concordato de 1953 en sus numerosos centros propios y en los públicos. En estos años, se añadía también que, si hasta entonces, no había tenido problema en que su alumnado perteneciera casi exclusivamente a las clases media y alta, empezaba a cuestionárselo pues se sentía llamada a dar prioridad a los grupos sociales más desfavorecidos. Por todo ello, con inteligencia y más de forma indirecta que directa, no dejó de estar atenta y conseguir la preservación de sus intereses. Mencionemos a este respecto la enconada oposición del Sindicato Vertical de Enseñanza y de la FERE a la financiación de la Ley, oposición que ya mostraron al primer y segundo Plan de Desarrollo acusándolos de favorecer la competencia desleal de las escuelas estatales al tiempo que reclamaban subvenciones para los centros privados. De hecho, consiguieron mantener sus privilegios. Así, por un lado, el artículo sexto de la LGE le reconocía todas las prerrogativas consignadas en el Concordato y en la legislación franquista; ${ }^{62}$ y, por otro, los artículos 94 y 96 abrían las puertas a los conciertos. ${ }^{63}$

En tercer lugar, hemos de señalar que uno de los mayores obstáculos para la adecuada aplicación de la Ley provino de quienes debían aplicarla. Sin minusvalorar las aportaciones a la educación secundaria y universitaria, la mayor de la Ley fue, sin duda, la Educación General Básica (EGB) que sustituía con absoluta innovación la enseñanza primaria y el bachillerato elemental. Iba a comprender ocho cursos entre los seis y los trece años

62 Ley General de Educación, artículo 6.

63 Ley General de Educación, artículos 94.4 y 96.1. 
(artículo 15.2); sería obligatoria y gratuita (artículo segundo, dos); igual para todos (artículo 15.1); orientada a la formación más que a la adquisición de conocimientos (artículo 16); estructurada en áreas de actividad educativa y no de asignaturas (artículo 17); la metodología debía fomentar la originalidad y creatividad de los escolares, así como el desarrollo de aptitudes y hábitos de cooperación, mediante el trabajo en equipo de Profesores y alumnos (artículo 18); la valoración del alumno se haría en relación a su propia capacidad y quienes no alcanzaren una evaluación satisfactoria al final de cada curso, pasarán al siguiente, pero deberán seguir enseñanzas complementarias de recuperación (artículo 19). Toda una revolución respecto a lo que venía siendo en España la enseñanza primaria y el bachillerato elemental como había precisado el Libro Blanco. ${ }^{64} \mathrm{Y}$ sin duda merecedora de todo elogio si no fuera porque había olvidado la advertencia que le había hecho el Comité Internacional que se había constituido para la reforma: «Probablemente el problema crucial y más difícil para asegurar el éxito de las innovaciones sea el reentrenamiento y formación del profesorado para su adaptación a los nuevos métodos. En el mejor de los casos, esto requiere un esfuerzo largo y paciente y una gran imaginación». ${ }^{65}$

En este punto el equipo de Villar Palasí reiteró uno de los más frecuentes fallos de las reformas "desde arriba», no darse cuenta de que quien ha de realizarla es el profesorado, el magisterio en el caso de la EGB. Y, sin embargo, como se ha escrito,

Es más que una hipótesis afirmar que quienes hacen las reformas escolares emanadas desde el poder son los docentes, es decir, la práctica; qué duda cabe que para analizar el correlato entre la propuesta y la realidad es útil conocer las colaboraciones o resistencias de los docentes, acercarse a su vida cotidiana, reparar en sus actitudes y en las acciones que conforman hábitos mentales y, por ende, también profesionales. ${ }^{66}$

\footnotetext{
64 Ministerio de Educación y Ciencia, La educación en España, 17-18.

65 Informe final del Comité de Cooperación Internacional para la reforma de la educación en España. 1969, 13: https://redined.mecd.gob.es/xmlui/bitstream/handle/11162/82858/00820093002260.pdf?sequence $=1$ \&isAllowed $=\mathrm{y}$ (consultado el 2 de febrero de 2021).

66 Juan Manuel Fernández Soria, «La nueva historia política de la educación», Historia de la Educación 25 (2006): 88.
} 
Así pues, el buque insignia de la reforma, la EGB, dependía de las maestras y maestros que en aquellos años estaban en activo. La mayoría contaba con una formación escasísima ${ }^{67}$ y con unos salarios y unas condiciones de vida deprimentes. ${ }^{68} \mathrm{Y}$ no solo no estaban preparados, sino que tampoco había en el panorama pedagógico español un número suficiente de expertos para esta tarea.

El Ministerio, como suele suceder, sucumbió a la prisa, como si una reforma de tan gran envergadura pudiera llevarse a cabo simplemente decretándola a través del Boletín Oficial del Estado (BOE). Una reforma impuesta desde arriba, una manifestación más de Despotismo Ilustrado. Como si magisterio y profesorado fuesen para el Ministerio sumisos subordinados más que colaboradores.

Desde el Ministerio se confió en los Institutos de Ciencias de la Educación (ICE), centros piloto y cursillos como medios, prácticamente únicos, para ayudar a centros y profesorado a aplicar la Reforma. Y ciertamente los ICEs han sido núcleos de trabajo y reflexión durante largos años y han creado (donde no la había) una cierta tradición de investigación y formación permanente del profesorado. Pero no podían asumir y con tanta inmediatez la preparación de todo el profesorado para la Reforma. ${ }^{69}$

Por último, en cuarto lugar, señalemos la oposición de quienes abiertamente se manifestaban en contra de cualquier propuesta gubernamental. La puesta en marcha de la LGE coincide con el final del franquismo y este fue un período de ascenso y consolidación de movimientos sociales, ${ }^{70}$ en general, y de resistencia, oposición y rebeldía al régimen franquista. La misma debilidad física de Franco y la incapacidad del Régimen para dar respuesta a su constante y generalizada contestación hacían pensar que no podía estar muy lejano su final. Por lo tanto, la

\footnotetext{
67 Agustín Escolano Benito, «Las Escuelas Normales. Siglo y medio de perspectiva histórica», Revista de Educación 269 (1982): 55-76

68 Ramón Navarro Sandalinas, «La Ley Villar y la Formación del Profesorado», Revista de Educación n. ${ }^{\circ}$ ext. «La Ley General de Educación veinte años después» (1992): 209-236.

69 José L. Castillejo Brull, «Los I.C.E.s y la formación del profesorado», Revista de Educación 269 (1982): 43-54.

70 Iván Bordetas Jiménez: «A vueltas con el franquismo, el cambio político y los movimientos sociales» en Nosotros somos los que hemos hecho esta ciudad. Autoorganización y movimiento vecinal durante el tardofranquismo y el proceso de cambio político (Tesis doctoral, Universidad Autónoma de Barcelona, 2012: 25-76)
} 
sociedad española se encontraba en circunstancias muy propicias para dar por terminada una etapa y propiciar otra.

Esta situación facilitó que, en relación a la LGE, se diera una doble actitud entre los grupos más politizados: el rechazo y la exigencia. De una parte, se la rechazaba por venir de autoridades no democráticas; de otra, se exigía al Ministerio al máximo todo lo que había en la Ley de avanzado, en especial, lo relativo a una total escolarización en condiciones adecuadas y a una completa gratuidad. Y ambas exigencias el Ministerio no estaba en condiciones de cumplirlas de modo instantáneo. ${ }^{71}$

Existía, además entre el profesorado, una amplia penetración del análisis de la enseñanza capitalista desde planteamientos marxistas y anarquistas. Había una clara influencia de las corrientes más o menos utópicas proclamadas en el Mayo francés del 68; de las críticas a la escuela burguesa que llegaban de Estados Unidos y de Italia; y, sobre todo, en algunos círculos del profesorado, hubo una gran influencia de textos de sociólogos críticos franceses como La reproducción, de Bourdieu-Passeron, Sobre la ideología y el Estado. Aparatos ideológicos del Estado, de Althusser, o La escuela capitalista en Francia, de Baudelot-Establet. ${ }^{72}$ Sus denuncias y planteamientos encontraron un gran eco en parte del magisterio y profesorado españoles, ávidos de guías y argumentos con los que descalificar el sistema educativo existente.

Unidos, todos estos obstáculos y resistencias convirtieron la puesta en marcha de la Ley en una tarea sumamente penosa y a la que costaba reconocerle los medidos logros que iba cosechando. Con razón se ha hablado de la «contrarreforma» que conoció la Ley desde el mismo instante de su gestación.

\section{CONTROVERSIAS. UNA VALORACIÓN DE LA LEY}

La política es uno de los ámbitos más propicios para la proliferación de controversias. Múltiples personas y grupos, con posiciones, opiniones e intereses diversos, cuando no rivales y hasta contrapuestos, favorecen

\footnotetext{
71 Jaume Carbonell, «De la Ley General de Educación a la alternativa de escuela pública. Algunas notas introductorias sobre los movimientos sociales en el sector de la enseñanza», Revista de Educación n. ${ }^{\circ}$ ext. «La Ley General de Educación veinte años después» (1992): 237-255.

72 Carbonell, «De la Ley General de Educación», 237-255.
} 
que constantemente surjan y se cultiven todo tipo de polémicas. Por eso hubiera sido impensable que no se dieran ante la reforma educativa de los 70. Al abordarlas lo hacemos teniendo en cuenta lo que suponen como valoración de la Ley.

En este caso, además, estamos ante una reforma decididamente modernizadora pero llevada a cabo dentro de un régimen autoritario y fuertemente conservador. Por lo tanto, sus planteamientos y, sobre todo, su puesta en práctica, darán lugar a intensas controversias que, en unos casos, serán por lo que tiene de innovación y, en otros, por no haberlo sido lo suficiente o no haber logrado todo y en la forma y el tiempo en los que se esperaba e incluso se comprometió. Algunas de estas controversias, no poseen una interpretación unívoca, sino que proceden de vivencias y están sujetas a vinculaciones. Por ello mismo, son más discutibles y comprensibles.

De las que se han dado -algunas todavía persisten con mayores o menores modificaciones- destacaríamos cuatro: la cacareada bajada de nivel de conocimientos al término de la educación obligatoria; la financiación con dinero público de la enseñanza privada con la consiguiente contraposición e incluso competición con la enseñanza pública; en tercer lugar, la integración de la Formación Profesional en el sistema educativo categorizada como «la hermana pobre» del mismo; y, finalmente, algunas de las decisiones tomadas a raíz de la Ley de la Memoria Histórica.

Respecto a la primera, es relativamente frecuente encontrar en este sentido opiniones que se quejan del bajísimo nivel cultural del alumnado al término de sus estudios obligatorios. Las expresan cualquier persona de forma desahogada, literatos y personas relevantes de la cultura en artículos periodísticos ${ }^{73}$ y profesorado que funcionó cuando el sistema expulsaba a quienes no se adaptaban al mismo o se manifiesta cansado del ejercicio profesional. En algunos casos merecerían muy poca atención académica. Es demasiado evidente en ellas el componente

\footnotetext{
73 Como ejemplos claros encontramos reiteradamente artículos de Javier Marías, «Profesores desesperados», El País, Madrid, 9 de octubre de 2005; o de Arturo Pérez-Reverte, "Permitidme tutearos, imbéciles», XL Semanal, Madrid, 5 de febrero de 2021. A veces adopta una expresión más estructurada como, por ejemplo, Antonio Moreno Castillo, Panfleto antipedagógico (Barcelona: El Lector Universal, 2006).
} 
subjetivo, ${ }^{74}$ su carga de nostalgia o su cansancio o incapacidad para afrontar los retos de una tarea como la educación que exige esfuerzo y entrega constantes y permanentemente una actitud optimista y proyectada al futuro. Con todo, su generalización aconseja afrontarlas siquiera mínimamente.

Digamos, primeramente, que en demasiadas ocasiones llama la atención la inadecuación de muchas comparaciones, absolutamente tramposas. ¿Cómo establecer relaciones entre la minoría que superaba el bachillerato elemental antes de la LGE (18\% de los escolarizados que no de toda la población escolarizable $)^{75}$ con la totalidad que, después de su aprobación, estaba obligada a llegar al final la EGB? ¿No hay tras ellas demasiado clasismo? ¿No hay un rechazo a la generalización y democratización de la educación? Muchas veces, se diría que no son conscientes de no ver la diferencia entre una cultura elitista y fuertemente memorística y literaria, referida al pasado y la que podríamos entender como "formación general» con saberes mucho más abiertos a la vida real y el presente. Tampoco que no se reconozca la diferencia entre tener solo un alumnado procedente de familias en las que todos sus miembros tuvieron una extensa escolarización y un alumnado que procede de la totalidad de las familias de una sociedad.

Pero sobre todo parece que no comprenden o no aceptan el sentido de la reforma del 70 y su esfuerzo modernizador y democrático. Esta, coherentemente con su inequívoco compromiso con el derecho a la educación y con su voluntad de que una educación básica abarcara obligatoriamente a toda la población, ${ }^{76}$ optó por la escolarización comprensiva (comprehensive school). Y, digámoslo abiertamente, no se trata de una metodología didáctica que facilite la tarea del profesorado, sino de una política educativa. Por supuesto, no se quiere renunciar a conseguir el mejor aprendizaje, pero en su intención primaria se persigue la búsqueda de logros más relacionados con la equidad, la igualdad de oportunidades o el bienestar de los alumnos que con una eficacia instructiva o con un

\footnotetext{
74 «Cómo a nuestro parecer, cualquier otro tiempo pasado fue mejor» que escribía Jorge Manrique ya en el siglo XV y donde dejaba clara la presencia de la subjetividad en este tipo de opiniones.

75 Ministerio de Educación y Ciencia, La educación en España, 24.

76 Ministerio de Educación y Ciencia, La educación en España, 206.
} 
trabajo más fácil para el profesorado. ${ }^{77}$ Ahora bien, la educación comprensiva no es fácil ni barata. No segregar al alumnado según su rendimiento escolar exige, cuando menos, una muy buena formación del profesorado, un equipo pedagógico en los centros -no solo profesorado- y además nunca perder de vista la ineludible relación escuela-sociedad. No se puede ignorar que los factores sociopolíticos y económicos siempre condicionan la realidad de la escuela, ni dejar de tener presente que no es lo mismo trabajar con un alumnado perteneciente a familias de clase media y alta que con otro que incluye a la totalidad de la población escolar. Por lo tanto, antes de rechazar el objetivo modernizador y democratizador de la LGE, hay que examinar si el fallo está en la propuesta o en la insuficiente dotación económica, su aplicación apresurada, la falta de preparación del profesorado y del sistema educativo para su puesta en práctica y, finalmente, en el hecho de que en una sociedad excesivamente desigual en todos los demás órdenes siempre entrañará especiales dificultades la educación comprensiva.

La segunda materia importante que ha dado lugar a controversias estaría, en nuestra opinión, en la financiación pública de la enseñanza privada. Nos parece que ya existía una velada contradicción entre las ideas y planteamientos del equipo ministerial en relación con la función del Estado en la educación y la aceptación de la fuerza que tenía la Iglesia, tanto por su presencia en las altas esferas del Régimen como por la que suponían sus numerosos centros educativos. Ella era el principal propietario y gestor de casi toda la enseñanza privada y esta tenía una presencia desproporcionada, sobre todo en la enseñanza media. ${ }^{78}$

\footnotetext{
77 «Para empezar, las escuelas deben ser comprensivas, esto es, los alumnos de diferentes contextos socioeconómicos y distintos niveles de rendimiento escolar deben ser educados en las mismas escuelas y en las mismas clases. [...] Poner a todos los alumnos en las mismas escuelas supone admitir que a) todos esos alumnos tienen el mismo valor como seres humanos; b) todos tienen amplias capacidades innatas con el mismo abanico de ellas dentro de cada grupo socioeconómico; y c) todos ellos pueden beneficiarse más o menos de una educación similar, siendo capaces de vivir una "buena vida" (que no difiere fundamentalmente de una clase a otra) y estando igualmente llamados para hacerlo»: Clive Beck, Better Schools. A Values Perspective (Bristol, The Falmer Press, 1990), 17. Citado en EURYDICE, Una década de reformas en la educación obligatoria de la UE (1984-1994) (Bruselas: Unidad Europea EURYDICE, 1997), 19.
}

78 Ministerio de Educación y Ciencia, La educación en España, 69. Ahí se puede ver el porcentaje de la enseñanza oficial respecto al total tanto en España como en los principales países europeos. En enseñanza media, destaca el 20,34\% de España frente a la mayoría de los países en los que es absolutamente mayoritaria (en tres supera el $90 \%$, en otros tres el $80 \%$ y en otros tres el $70 \%$ ). En los tres países donde tampoco es mayoritaria la enseñanza pública, tenía, sin embargo, un porcentaje 
La denuncia del Libro Blanco de las desigualdades en educación y la insistencia en el derecho a la educación y el deber del Estado de garantizarla induciría a pensar que fue la presión de la Iglesia -a la que ya nos hemos referido en estas mismas páginas- quien consiguió que se asumiese la financiación pública de la enseñanza privada a fin de mantener la gratuidad en los niveles obligatorios. Además, como hemos indicado en páginas anteriores, el esfuerzo modernizador de los promotores de la reforma suponía una clara preeminencia del Estado y su papel en la educación frente a las pretensiones de la Iglesia de que fuera subsidiario. El Libro Blanco dejaba claro que la enseñanza privada estaría bajo la tutela y dirección del Estado, aunque ya asumía que «El Estado proporcionará a los Centros de enseñanza no estatal ayuda», si bien lo hacía condicionadamente: «en la medida en que estos beneficien a los sectores sociales menos favorecidos económicamente y en función del nivel y calidad de su rendimiento educativo».79 Quedaba apuntada la incógnita de cómo compaginar que toda la educación básica fuese obligatoria y gratuita y a la vez admitir la existencia de centros privados que solo serían subvencionados si acogían a unos sectores determinados del alumnado.

La Ley nos parece que mantuvo también una cierta contradicción en este mismo sentido cuando, por un lado, afirmaba con la máxima intensidad la voluntad de superar las desigualdades en educación y, por otro, aceptaba los conciertos entre el Estado y las instituciones privadas para garantizar la gratuidad de en los tramos obligatorios. Así, en la introducción expresa con rotundidad su compromiso con la igualdad:

El período de Educación General Básica, que se establece único, obligatorio y gratuito para todos los españoles, se propone acabar en el plazo de implantación de esta Ley con cualquier discriminación y constituye la base indispensable de igualdad de oportunidades educativas, igualdad que se proyectará a lo largo de los demás niveles de enseñanza. ${ }^{80}$

\footnotetext{
bastante superior al que entonces existía en España. Así, Bélgica $(41,21 \%)$, Portugal $(38,88 \%)$ y Holanda $(31,89 \%)$.

79 Ministerio de Educación y Ciencia, La educación en España, 241.

80 «Ley 14/1970, de 4 de agosto, General de Educación y Financiamiento de la Reforma Educativa», BOE, 6 de agosto de 1970.
} 
Y en el artículo 15.1 vuelve a insistir: «La Educación General Básica tiene por finalidad proporcionar una formación integral, fundamentalmente igual para todos [...]».

Sin embargo, la Ley no tenía más remedio que reconocer a la Iglesia todos los derechos -más bien privilegios- que le otorgaba el Concordato de $1953^{81}$ lo cual suponía que dejaba de ser igual para todos. Y también aceptaba la financiación directa del Estado a la enseñanza privada. Así, se comprometía a que toda la educación obligatoria fuera gratuita y para ello el Estado subvencionaría a los centros no estatales de forma completa mediante conciertos. ${ }^{82}$

Probablemente la asfixia económica del Ministerio impidió cumplir lo que prescribía la Ley. Como remedo, se aprobó una normativa provisional, objeto de sucesivas modificaciones que dio lugar a un progresivo incremento de la cuantía de las subvenciones. El resultado fue paradójico: hubo una elevada participación estatal en la financiación de la enseñanza privada y no entraron en funcionamiento el sistema de contrapartidas ni las exigencias que pretendía la Ley. ${ }^{83}$

La Iglesia siempre ha justificado sus demandas en el derecho de los padres a elegir la educación que deseen para sus hijos, especialmente en su dimensión religiosa y moral, derecho reconocido en la LGE (artículo 5.3) y respaldado con anterioridad por la «Declaración Universal de los Derechos Humanos» (artículo 26), y posteriormente también recogido en la Constitución española (artículo 27). Ya en los años en los que se producía un constante incremento de la financiación pública a la

81 Ley General de Educación, Artículo 6.1.

82 «Artículo 94.4: a) En el más breve plazo, y como máximo al concluir el período previsto para la aplicación de la presente Ley, la Educación General Básica, así como la Formación Profesional de primer grado, serán gratuitas en todos los Centros estatales y no estatales. Estos últimos serán subvencionados por el Estado en la misma cuantía que represente el coste de sostenimiento por alumno en la enseñanza de los Centros estatales, más la cuota de amortización e intereses de las inversiones requeridas. b) A los efectos de la referida subvención, se establecerán los correspondientes conciertos, de conformidad con lo que determina el artículo noventa y seis de esta Ley.».

83 José M. Díaz Lema, Los conciertos educativos en el contexto de nuestro derecho nacional y en el derecho comparado (Madrid: Marcial Pons, 1992), citado en Ana Villarroya Planas, La financiación de los Centros Concertados (Madrid, Ministerio de Educación, Cultura y Deporte. Secretaría General de Educación y Formación Profesional. Centro de Investigación y Documentación Educativa, 2000): 89. 
enseñanza privada, uno de los autores de la Ley planteaba que la libertad de enseñanza no debería contribuir a diferencias y discriminaciones que terminan perjudicando a los más necesitados; que el interés de las familias de proporcionar la mejor educación para sus hijos sería de mayor valor ético si se convirtiera en un interés «social» que beneficiara también a los hijos de los demás; y que si se dan desigualdades, tendrían que ser en beneficio de los más necesitados, no al revés. ${ }^{84}$

Desde la perspectiva actual, podemos decir que los conciertos vieron la luz con la Ley Orgánica del Derecho a la Educación (LODE), la primera ley sobre la educación no universitaria que promulgó el primer gobierno socialista de la democracia en 1985; que paulatinamente han ido disminuyendo sus exigencias y se ha incrementado la libertad de elección siendo sobre todo las clases medias quienes más han sabido aprovecharla; ${ }^{5}$ y que se ha dado un gran incremento de la financiación pública que ha tenido un carácter regresivo pues han sido las clases medias y altas sus principales beneficiarias. ${ }^{86}$ Finalmente, reconozcamos que la mayoría de la investigaciones constatan que, en términos generales, la libertad de elección de centros no es utilizada por las familias para elegir una educación conforme a sus convicciones religiosas o morales, sino para buscar una mejora de las posibilidades de sus hijos en una sociedad competitiva así como para que se encuentren en un ambiente que implica segregación social. ${ }^{87}$

La tercera materia a la que nos referiríamos como objeto de controversia sería la Formación Profesional (FP). También aquí destaca el impulso modernizador que supuso la reforma de los 70. Hasta entonces, la FP estaba separada del sistema educativo, como una modalidad independiente y sin vías de acceso al mismo, lo que le suponía perjuicios y un innegable menosprecio social. La LGE empezó por darle un enfoque

\footnotetext{
84 Cuadernos de Pedagogía, «La opinión de... José Blat Gimeno» (Sobre el informe de la Comisión Evaluadora de la LGE. Encuesta realizada a diferentes personalidades del mundo educativo, desde representantes de la Comisión Evaluadora de la Ley General de Educación de 1970, hasta representantes de diferentes sectores educativos)», Cuadernos de Pedagogía 18 (1976), s.p.

85 Villarroya Planas, La financiación de los Centros Concertados: 302-303.

86 Villarroya Planas, La financiación de los Centros Concertados, 306.

87 Miquel Ángel Alegre Árbol y Ricard Benito, "¿En qué se fijan las familias a la hora de escoger la escuela de sus hijos?: factores de elección y descarte escolar en la ciudad de Barcelona", Profesorado: Revista de currículum y formación del profesorado 16, n. 3 (2012): 59-79.
} 
más amplio al que venía recibiendo y, de hecho, sustituyó su vinculación a una profesión concreta por el de familias profesionales. Pero, sobre todo, la principal novedad está en su integración plena en el sistema educativo y en hacerla beneficiaria de los principios generales que reclamaba para el mismo, es decir, la formación permanente de la persona, así como la interrelación con los restantes niveles. Añade, además, un intento de superar una dicotomía cerrada entre la formación general y la profesional al introducir en la EGB y, de forma más específica en el BUP, enseñanzas y actividades «técnico-profesionales» (EATP). 88

Si todo lo anterior era enormemente positivo, hay que señalar que no terminó de superar los rasgos que terminaron por hacer de ella la «hermana pobre» del sistema educativo. Entre ellos están su impartición en centros diferentes, la asignación de un profesorado específico y en algunas materias con menor titulación y, sobre todo, convertirla en la única salida del alumnado que «no quiere o no puede estudiar». Ya supone un problema la temprana bifurcación del sistema entre la rama orientada a la continuación de la formación y la otra, caracterizada por la preparación profesional; ahora bien, la doble titulación al finalizar la EGB -Graduado Escolar o simplemente Certificado de Escolaridad- ha hecho que, desde el comienzo, el alumnado con mejores expedientes y pertenecientes a clases medias y altas han accedido al BUP mientras que para quienes no habían conseguido los objetivos de la EGB la única opción era la FP. ${ }^{89}$

Quizás tengan un rango menor las controversias que han tenido lugar a raíz de los cambios de denominación que se han dado con motivo de la Ley de la Memoria Histórica. Consideramos que esta Ley viene a reparar clamorosas injusticias. Es hora ya de que encuentren la debida reparación todas las víctimas de la represión franquista y vean restaurada su dignidad. Nuestra mirada se dirige ahora al afán que algunos representantes municipales han desplegado para borrar los vestigios de la reforma educativa de los años 70 y sus autores. Nos parece que dicha reforma en conjunto, y especialmente si se tiene en cuenta el contexto en el que se realizó, fue meritoria, y sus autores demostraron inteligencia, valentía, generosidad y deseo de servir a la sociedad española

88 Ley General de Educación, artículos 17.1 y 26.

89 Ley General de Educación, artículo 20. 
propiciando su modernización a través de la reforma de la enseñanza. Estamos persuadidos de que la Ley de la Memoria Histórica es digna de empeños más justos, necesarios y provechosos.

Terminemos este apartado reconociendo que la LGE ha estado sometida a fuertes controversias en sus orígenes y desarrollo, como también muestra en su texto para este monográfico, aunque desde otro enfoque, Patricia Delgado Granados. Quisiéramos insistir en que, en unos casos, podemos atribuirles su origen a su mismo carácter modernizador que chocaba con concepciones e intereses socialmente asentados; en otros, a su insuficiente financiación, así como a las dificultades que tuvo para su puesta en práctica; y en otros a que, pese a su carácter positivo e innovador general, no satisfacía plenamente lógicas aspiraciones ni cumplía adecuadamente sus propios compromisos y prescripciones.

\section{PARA FINALIZAR}

La LGE ha sido objeto de diferentes análisis y valoraciones. Lo justifica la misma sustantividad de la Ley, cuya importancia ponen de manifiesto incluso quienes la censuran. No nos detendremos en analizar las críticas que se han hecho a la Ley -algunas ya las hemos deslizado en las páginas precedentes-, como la falta de concreción del Libro Blanco, su ambivalente estatismo, que tanto pretende huir de la subsidiariedad del sistema público como favorecer a la enseñanza privada, ${ }^{90}$ su mezcla de progreso y regreso, el ser un instrumento al servicio de la reproducción de clases con «renovados» procedimientos y una semántica nueva (igualdad de oportunidades, racionalización, selección en función de las capacidades...), ${ }^{91}$ el haberse erigido en recurso de legitimación para la supervivencia del Régimen al transferir a la educación la justificación del orden social desde nuevas bases culturales (meritocracia, valía individual, sistema educativo psicologizado... $)^{92}$ poniéndose así al servicio de la política en una especie de «huida hacia adelante»...93 Y, no sin razón,

\footnotetext{
90 Armando Segura, Crítica del libro blanco y del proyecto de ley de educación (Barcelona: Editorial Novaterra, 1970), 80.

91 Carlos Lerena Alesón, Escuela, ideología y clases sociales en España. Crítica de la sociología empirista de la educación (Barcelona: Ariel, 1976), 273-277.

92 Ortega, «Las ideologías de la reforma educativa de 1970», 36-37, 43.

93 Puelles, «Tecnocracia y política», 19.
} 
también se ha reparado en las llamativas omisiones de la Ley (presencia del profesorado en la reforma, objetivos de las etapas educativas, instalaciones escolares, zonas rurales...). ${ }^{94}$ Incluso hay quien afirma que la Ley «no alcanzó ninguno de los objetivos propuestos -escolarización total, gratuidad, reforma pedagógica, etcétera»-. ${ }^{95}$ Abonaría esta opinión el déficit, casi diez años después, de puestos escolares, la inequitativa distribución de los recursos, la persistencia de las desigualdades, incluso regionales, las deficiencias en la calidad de la enseñanza, etc. ${ }^{96}$

Reconociendo algunas de las valoraciones mencionadas, también debemos consignar otras de diferente signo. Como que la LGE fue un manifiesto contra la política educativa franquista, y un proyecto -ciertamente ilustrado- inspirado en principios modernizadores, que hablaba de participación, democratización, de derecho a la educación e igualdad de oportunidades, que reconocía la educación como servicio público fundamental y el consiguiente protagonismo del Estado en ella, y que volvía de nuevo la mirada a Europa, como en la mejor tradición española en busca de soluciones. Por eso, posiblemente este nuevo aire pedagógico -aunque conteniendo mucho de apariencia y de burocracia- fuera un factor más de cuantos contribuyeron a aliviar la tensión social y a preparar la transición política en España, como aventuró Diez Hochleitner. ${ }^{97}$

Es innegable que la LGE -«Madre de toda la legislación educativa posterior» en expresión de Raimundo Cuesta98-, al margen de la finalidad política que albergaran sus creadores, retomó los principios de la escolarización universal y gratuita y de la escuela comprensiva, y recuperó la

\footnotetext{
94 Pamela O' Malley, La educación en la España de Franco (Madrid: Gens, 2010), 106-107.

95 Valeriano Bozal, «De la escuela heredada del franquismo, a la escuela pública», El País (Madrid), 18 de septiembre de 1977.

96 Ministerio de Educación y Ciencia, España. El desarrollo de la educación en 1977-78 y 1978-79. Informe a la $37^{a}$ Reunión de la conferencia Internacional de la Educación, Ginebra, julio 1979 (Madrid: MEC, 1979), 9-10, 17.

97 Díez Hochleitner, «La reforma educativa», 497-498.

98 Cuesta Fernández, Raimundo, «A modo de presentación genealógica: El presente y el pasado de la educación y el futuro del estado del bienestar», en Cuesta Fernández, Raimundo, Enrique Díez Gutiérrez, Juan Mainer Baqué y Julio Mateos Montero, Reformas y modos de educación en España: entre la tradición liberal y la tecnocracia. Separata de la Revista de Andorra, edición del Centro de Estudios Locales de Andorra, 2011: 24.
} 
idea de la educación como palanca de desarrollo económico, de mejora, de cambio y de movilidad social. La Ley Villar trajo consigo un repertorio doctrinal importante, una apertura epistemológica desconocida hasta entonces. Por eso se suele admitir que «la concepción global de la reforma era moderna», como lo demostraría que otra reforma, la de 1990 que la sustituyó con el Partido Socialista en el poder, volviera sobre algunos de sus principios no implantados o escasamente desarrollados, como el de la comprensividad. ${ }^{99}$ Para otros, su sombra llega más allá de la reforma de 1990, proyectándose «hasta la más reciente legislación de nuestro tiempo». ${ }^{100}$

Negada en su tiempo desde dentro y fuera del Régimen, y, en el nuestro, elogiada por unos en sus planteamientos pedagógicos y criticada por otros en sus propósitos políticos, cuando ahora se cumplen cincuenta años de su aprobación, la LGE no ha logrado sacudirse la mancha de ser una ley emanada en el franquismo que buscó remedios en las recomendaciones internacionales y quiso responder a las exigencias del desarrollismo capitalista. Con todo, estas intenciones no han sido las que le han procurado el desfavor de la desmemoria, sino, sobre todo, que fuera una ley nacida en un régimen dictatorial; y ese fue su «estigma: el de ser una ley franquista». ${ }^{101}$ A pesar del cual, y a despecho de la aplicación práctica de la reforma, la Ley General de Educación de 1970, fue, al menos en su programa propositivo, una ley para la modernización de España.

\section{Nota sobre los autores}

Juan Manuel Fernández-Soria es catedrático de Teoría e Historia de la Educación de la Universidad de Valencia. Se ha especializado en Política educativa y en Historia de la Educación española contemporánea. En este último ámbito ha dedicado parte de su atención al estudio de la educación durante la Guerra Civil española, una de cuyas contribuciones en esta materia le valió el VII «Premio José Manuel Esteve», convocado por

\footnotetext{
99 Puelles, «Tecnocracia y política», 24.

100 Cuesta, «A modo de presentación», 24.

101 Viñao, «La Ley General de Educación», 130.
} 
la Universidad de Málaga. El estudio de la memoria histórica ha constituido otra de sus destacadas líneas de investigación, por uno de cuyos trabajos, dedicado a la represión del Magisterio primario y por otros estudios de esta temática que le siguieron, fue galardonado, junto a Carmen Agulló, con el «Premi Dones Progressistes» en su XV $\mathrm{XV}^{\mathrm{a}}$ edición, otorgado por la Federació de Dones Progressistes de la Comunitat Valenciana. En el campo de la Política Educativa ha contribuido a consolidar el Grupo de Investigación reconocido por la Universidad de Valencia -«Políticas Educativas, Interculturalidad y Sociedad» (POLISOC)-, que dirige. En los últimos años se ha centrado en el estudio de las relaciones de poder en la profesión docente, el papel del Estado en la educación, la educación moral y cívica, las influencias internacionales en la política educativa española, los procesos de socialización y legitimación política a través de la educación, el derecho a la educación, la libertad de enseñanza y la identidad cultural. El resultado de estas investigaciones los ha dado a conocer en varios libros, ponencias y artículos publicados en revistas especializadas. Actualmente dirige la colección «Márgenes» de la Editorial Tirant Lo Blanch, que integra hasta el momento cerca de 90 títulos.

Diego Sevilla Merino es doctor en Filosofía y Letras (Sección Pedagogía) por la Universidad de Málaga y Profesor en la Universidad de Granada desde el curso 1982-1983 donde con el perfil de «Política y Legislación Educativas» y dentro del área Teoría e Historia de la Educación ha obtenido plaza de Profesor Titular de Universidad (1987) y Catedrático (2011). En la actualidad está jubilado. Su investigación y publicaciones se han orientado preferentemente al estudio del sistema educativo tanto en sus diferentes etapas como en su relación con la sociedad y los ha realizado a menudo desde un enfoque histórico. Ha sido IP en varios Proyectos de Investigación: «Articulación de políticas públicas en la Formación Profesional específica a través del diseño de competencias» (SEJ 1174) (2006-2009); «La incidencia de la elección de centros educativos en los procesos de inclusión y exclusión social en la Comunidad Autónoma de Andalucía»(SEJ2006-08828/EDUC) (2006-2009); «Dinámicas de privatización exógenas y endógenas en y de la educación: la implantación del modelo de cuasimercado en España.» EDU2010-20853 (2010-2013). Pertenece a la Sociedad Española de Historia de la Educación y a la Sociedad Española de Educación Comparada. Ha formado 
parte del Consejo Escolar de Andalucía en su Comisión Permanente. Dentro de la Universidad de Granada, ha ocupado los puestos de Director y Secretario del Departamento de Pedagogía, Vicedecano Comisario para la formación de la Facultad de CC. de la Educación y Director del Secretariado de estudios del Tercer Ciclo y Doctorado.

\section{REFERENCIAS}

Alegre Árbol, Miquel Ángel y Ricard Benito, «¿En qué se fijan las familias a la hora de escoger la escuela de sus hijos?: factores de elección y descarte escolar en la ciudad de Barcelona», Profesorado: Revista de currículum y formación del profesorado 16, n. 3 (2012): 59-79.

Beck, Clive, Better Schools. A Values Perspective. Bristol: The Falmer Press, 1990. Blat Gimeno, Amparo. «El Llibre Blanc i la Lley General d’ Educació de 1970 segons José Blat Gimeno». Educació i Història. Revista d' Història de l' Educació 36 (2020): 161-175.

Bordetas Jiménez, Iván. «A vueltas con el franquismo, el cambio político y los movimientos sociales", en Nosotros somos los que hemos hecho esta ciudad. Autoorganización y movimiento vecinal durante el tardofranquismo y el proceso de cambio político, 25-76. Tesis doctoral, Universidad Autónoma de Barcelona, 2012.

Carbonell, Jaume. «De la Ley General de Educación a la alternativa de escuela pública. Algunas notas introductorias sobre los movimientos sociales en el sector de la enseñanza». Revista de Educación, n. ${ }^{\circ}$ ext. «La Ley General de Educación veinte años después» (1992): 237-255.

Carnero, Teresa. «Modernización política: una propuesta de análisis». Historia Contemporánea 4 (1990): 133-144.

Carreras, Albert y Xavier Tafunell (coords.). Estadísticas históricas de España, ss. XIX y XX. Bilbao: Fundación BBVA, 2005.

Castillejo Brull, José Luis. «Los I.C.E.s y la formación del profesorado». Revista de Educación 269 (1982): 43-54.

Cuesta Fernández, Raimundo. «A modo de presentación genealógica: El presente y el pasado de la educación y el futuro del estado del bienestar», en Cuesta Fernández, Raimundo, Enrique Díez Gutiérrez, Juan Mainer Baqué y Julio Mateos Montero, Reformas y modos de educación en España: entre la tradición liberal y la tecnocracia, 19-30. Separata de la Revista de Andorra, edición del Centro de Estudios Locales de Andorra, 2011.

Cuadernos de Pedagogía. «Villar Palasí, diez años después. Entrevista realizada a José Luis Villar Palasí, diez años después de la implantación de la Ley 
General de Educación de 1970. Valoración de la aplicación de la citada ley y exposición de las ideas que subyacen tras la misma». Cuadernos de Pedagogía 65 (1980): 23-25.

Díaz Lema, José M. Los conciertos educativos en el contexto de nuestro derecho nacional y en el derecho comparado. Madrid: Marcial Pons, 1992.

Díez Hochleitner, Ricardo. «Conferencia pronunciada por Don Ricardo Díez Hochleitner en el acto de apertura del IV Congreso Nacional de Pedagogía». Pamplona, octubre, 1967). Revista de Educación 201 (1969): 66-69.

Díez Hochleitner, Ricardo. «Palabras del Señor Ricardo Díez Hochleitner en la clausura del Seminario Internacional sobre Prospectiva de la Educación». Revista de Educación 215 (1971): 125-126.

Díez Hochleitner, Ricardo. «La reforma educativa de 1970. Su pequeña historia», en Ministerio de Educación y Ciencia, Simposium internacional sobre Educación e Ilustración. Dos siglos de reformas en la enseñanza. Ponencias, 477-498. Madrid: Centro de publicaciones -Secretaría General Técnica. Ministerio de Educación y Ciencia, 1988.

Escolano Benito, Agustín. «Discurso ideológico, modernización técnica y pedagogía crítica durante el franquismo». Historia de la Educación 8 (1989): 7-27.

Escolano Benito, Agustín. «Los comienzos de la modernización pedagógica en el franquismo: (1951-1964)»; Revista española de pedagogía 192 (1992): 289310.

EURYDICE. Una década de reformas en la educación obligatoria de la UE (19841994), Bruselas: Unidad Europea EURYDICE, 1997.

Fernández Soria, Juan Manuel. «La nueva historia política de la educación». Historia de la Educación 25 (2006): 71-103.

Gómez-Escalonilla, Lorenzo. «Educación para el desarrollo. OCDE, asistencia exterior y reforma de la enseñanza en la España tardofranquista». Foro de Educación 18, n. ${ }^{\circ} 2$ (2020): 127-148.

González-Delgado, Mariano. «Las influencias internacionales en el sistema educativo español durante el tardofranquismo: una nueva visión historiográfica», en Ideas educativas en perspectiva filosófica e histórica. Circulación, recepción y concreción en la práctica, ed. Jon Igelmo Zaldívar, 73-79. Salamanca: FahrenHouse, 2019.

Informe final del Comité de Cooperación Internacional para la reforma de la educación en España. 1969. https://redined.mecd.gob.es/xmlui/bitstream/handle/11162/82858/00820093002260.pdf?sequence=1\&isAllowed=y (consultado el 2 de febrero de 2021).

Lerena Alesón, Carlos. Escuela, ideología y clases sociales en España. Crítica de la sociología empirista de la educación. Barcelona: Ariel, 1976. 
Loff, Manuel. «La política cultural de los “Estados nuevos” español y portugués (1936-1945): tradicionalismo, modernidad y confesionalización». Revista de Occidente 223 (1999): 41-62.

Lorenzo Vicente, Juan Antonio. «Los "precedentes” del Libro Banco y de la Ley General de Educación, con especial referencia a la educación secundaria». Revista de Educación 316 (1998): 343-368.

Martin, Ó. J., y L. Delgado Gómez-Escalonilla, «Educational Reform, Modernization and Development. A Cold War Transnational Process», en Teaching Modernization. Spanish and Latin American Educational Reform in the Cold War, eds. Ó. J. Martin y L. Delgado Gómez-Escalonilla, 235-260 (New York: Berghahn Books, 2020).

Ministerio de Educación Nacional. La educación y el desarrollo económico-social. Planeamiento integral de la educación. Objetivo de España para 1970. Curso-Coloquio sobre planeamiento integral de la educación. Madrid: MEN, 1962.

Ministerio de Educación y Ciencia. La educación en España. Bases para una política educativa. Madrid: Secretaría General Técnica del MEC, 1969.

Ministerio de Educación y Ciencia. España. El desarrollo de la educación en 1977-78 y 1978-79. Informe a la $37^{a}$ Reunión de la conferencia Internacional de la Educación. Ginebra, julio 1979. Madrid: Ministerio de Educación y Ciencia, 1979.

Moreno Castillo, Antonio. Panfleto antipedagógico. Barcelona: El Lector Universal, 2006.

O’ Malley, Pamela. La educación en la España de Franco. Madrid: Gens, 2010.

Ortega, Félix. «Las ideologías de la reforma educativa de 1970». Revista de Educación, n. ${ }^{\circ}$ ext. «La Ley General de Educación veinte años después» (1992): 31-46.

Pasquino, Gianfranco. «Modernización», en Diccionario de Política, eds. Norberto Bobbio, Niccola Mateucci y Gianfranco Pasquino, I, 988-998. México-Buenos Aires: Siglo XXI, 2005.

Pérez Galán, Mariano, «La Ley General de Educación y el movimiento de enseñantes». Revista de Educación, n. ${ }^{\circ}$ ext. «La Ley General de Educación veinte años después» (1992): 311-321.

Puelles Benítez, Manuel de. «Tecnocracia y política en la reforma educativa de 1970». Revista de educación, n. ${ }^{\circ}$ ext. "La Ley General de Educación veinte años después» (1992): 13-29.

Serrano Pelegrí, Fernando. «La tramitación de la Ley General de Educación y Financiamiento del Sistema Educativo de 1970. Análisis desde una perspectiva político-educativa» (Tesis doctoral, Universidad CEU - Cardenal Herrera, 2016). 
Villar Palasí, José Luis. «España y el “Año Internacional de la Educación”. Alocución del excelentísimo señor don José Luis Villar Palasí, ministro de Educación y Ciencia, a través de Televisión Española, el día 16 de enero de 1970». Revista de Educación 206 (1969): 47-48.

Villar Palasí, José Luis. «Discurso del Ministro de Educación y Ciencia en la sesión inaugural del Seminario Internacional sobre Prospectiva de la Educación». Revista de Educación 215 (1971): 119-120.

Villar Palasí, José Luis. «Discurso del ministro de Educación y Ciencias ante el Pleno de las Cortes en defensa del Proyecto de Ley General de Educación y Financiamiento de la de la Reforma Educativa». Boletín Oficial de las Cortes Españolas. Diario de las Sesiones del Pleno, n. 2 (28 julio 1970): 29-35.

Villar Palasí, José Luis. "Discurso del ministro de Educación y Ciencia informando a la Comisión de Educación de las Cortes sobre la aplicación de la Ley General de Educación». Boletín oficial de las Cortes Españolas. Diario de las sesiones de comisiones. Comisión de Educación y Ciencia. Apéndice núm. 10 (14 febrero 1972): 3-19.

Villar Palasí, José Luis. «Discurso pronunciado por el Ministro de Educación y Ciencia, don José Luis Villar Palasí, al presentar ante la Comisión de Educación de las Cortes Españolas el proyecto de Ley General de Educación y de Financiamiento de la Reforma Educativa». Boletín Oficial de las Cortes Españolas. Diario de Sesiones de las Comisiones. Comisión de Educación y Ciencia, Apéndice n. ${ }^{\circ} 19$ (1 abril 1970): 2-12.

Villar Palasí, José Luis. «Introducción» a Ministerio de Educación y Ciencia. La educación en España. Bases para una política educativa, 7-11. Madrid: MEC, 1969).

Villarroya Planas, Ana. La financiación de los Centros Concertados. Madrid: Ministerio de Educación, Cultura y Deporte. Secretaría General de Educación y Formación Profesional. Centro de Investigación y Documentación Educativa, 2000.

Viñao, Antonio. Escuela para todos y modernidad en la España del siglo XX. Madrid: Marcial Pons, 2004.

Viñao, Antonio. "El sistema educativo español: evolución histórica», en Procesos y contextos educativos: enseñar en las instituciones de educación secundaria, coord. F. Imbernon, 13-33. Barcelona: Graó, 2010.

Viñao, Antonio «La Ley General de Educación de 1970: ¿final de una etapa? ¿comienzo de otra?», en Modernización educativa y socialización política. Contenidos curriculares y manuales escolares en España durante el tardofranquismo y la transición democrática, ed. Manuel Ferraz Lorenzo, 125-149. Barcelona: Ediciones Morata y Universidad de La laguna, 2020. 